\title{
Revisiting 1-hexene low-temperature oxidation
}

\author{
Xiangzan Menga, b, Anne Rodrigueza, Olivier Herbinet ${ }^{a}$, Tianyou Wangb ${ }^{\mathrm{b}}$, Frédérique \\ BattinLeclerc ${ }^{a}$, \\ a Laboratoire Réactions et Génie des Procédés, CNRS, Université de Lorraine, Nancy, France \\ ${ }^{b}$ State Key Laboratory of Engines, Tianjin University, Tianjin 300072, China
}

Published in Combustion and Flame (2017), 181, 283-299

https://doi.org/10.1016/j.combustflame.2017.03.031

\begin{abstract}
The low-temperature oxidation of 1-hexene has been studied in a jet-stirred reactor for temperatures from 500 to $1100 \mathrm{~K}$, at atmospheric pressure, for equivalence ratios from 0.5 to 2 with a high dilution in helium. Product formation has been investigated using gas chromatography, as well as laser-singlephoton-ionization time-of-flight mass spectrometry and cw-cavity-ring down spectroscopy. These two last techniques have allowed the quantification of ketene, $\mathrm{C}_{1}-\mathrm{C}_{3}$ alkylhydroperoxides, hexenyl hydroperoxides, $\mathrm{C}_{6}$ unsaturated ketohydroperoxides, and hydrogen peroxide.

Starting from a previous model generated automatically, a new model has been developed for 1-hexene oxidation by updating some determinant reaction kinetics based on newly published theoretical calculations. This new model allows a good prediction of most of the newly obtained experimental results, as well as satisfactory simulation of literature data obtained for the high-temperature oxidation in a high-pressure jet-stirred reactor, in a rapid compression machine, and in two shock tubes.
\end{abstract}

Keywords: Low-temperature oxidation; 1-Hexene; Jet-stirred reactor; Modeling 


\section{Introduction}

Since alkenes are important components of gasoline [1], the low-temperature oxidation kinetics (below $900 \mathrm{~K}$ ) of $\mathrm{C}_{5}-\mathrm{C}_{7}$ linear alkenes was often investigated [2-12]. However, the experimental studies concerning the low-temperature reactivity of the most studied $\mathrm{C}_{5}-\mathrm{C}_{7}$ alkenes, hexene isomers, which were obtained in a rapid compression machine [4] and in a jet-stirred reactor [10], were limited to stoichiometric conditions. The kinetics of several reactions important for alkene lowtemperature oxidation (e.g. reactions of alkenes with $\mathrm{OH}$ radicals [13] or reactions of peroxyradicals including a hydroxyl function [14]) was recently investigated using theoretical calculations. However, the last detailed kinetic models of hexene oxidation were published before 2011 by Mehl et al. [7,9] and by Bounaceur et al. [8], except in the case of 3-hexene [11]. In the last case, a model was recently proposed based on that of Mehl et al. [7,9], but with important kinetic parameter fitting and without taking the new theoretically calculated rate constants into account.

The first objective of the present work is then to continue the experimental study of Battin-Leclerc et al. [10] on 1-hexene oxidation made under stoichiometric conditions using a jet-stirred reactor (JSR) with gas chromatography analyses by studying two additional equivalence ratios $(0.5$ and 2$)$. The second goal is to expand the range of products analyzed during 1-hexene JSR oxidation by using two additional analytical techniques, cw-cavity-ring down spectroscopy (cw-CRDS) and laser-ionization mass spectrometry. These techniques have been recently shown successful in quantifying hydrogen peroxide, ketene and hydroperoxides during alkane oxidation [15]. Finally, the third purpose of this paper is to describe a new model for 1-hexene low-temperature oxidation based on recently published theoretical kinetic data.

\section{Experimental setup and procedure}

A heated isothermal jet-stirred reactor, already used in many organic compounds oxidation studies [16], has been connected to the three following analytical devices:

(1) Gas chromatographs (GCs) via a heated transfer line.

(2) A laser-single-photon-ionization time-of-flight mass spectrometer (SPI-TOF-MS) via capillarytube sampling.

(3) A cw-cavity-ring down spectroscopy (cw-CRDS) optical cell using the near-IR wavelength range via sonic probing.

More details about experimental procedure can be found in the Supplementary material (SM).

\subsection{Jet-stirred reactor and gas feeding}

The reactive mixture entered the spherical JSR made out of quartz through four nozzles, positioned in the center of the reactor. These nozzles were designed in order to ensure a perfect gas mixing and to avoid concentration gradients inside the reactor [17]. The reactor was warmed using Thermocoax resistance wires. The reaction temperature was measured by a type $\mathrm{K}$ thermocouple positioned at the center of the reactor. The pressure in the reactor $(\mathrm{P})$ was controlled using a needle valve positioned at the downstream of the reactor and taken equal to $106.7 \mathrm{kPa}$.

A stable, continuous stream of helium, oxygen and 1-hexene to the reactor was ensured thanks to Bronkhorst mass flow controllers. Helium and oxygen were provided by Messer (purities of $99.99 \%$ and 99.999\%, respectively). 1-Hexene was provided by ALFA AESAR (purity of 98\%) and used without further purification. The fuel flow rate to the reactor was controlled using a liquid Coriolis 
mass flow controller provided by Bronkhorst. The liquid flow was mixed with helium and passed through an evaporator. The fuel/helium blend was subsequently mixed with oxygen. The relative uncertainty in gas flow rates was approximately 5\%. To limit thermal gradients inside the reactor, prior to entering the spherical vessel, the gaseous mixture was heated to the reactor temperature in a quartz annular pre-heating zone also using Thermocoax resistance wires. The residence time in this zone was negligible compared to the residence time in the reactor $(\tau)$ which was taken equal to $2 \mathrm{~s}$.

\subsection{Gas chromatography analyses}

The gases leaving the reactors were analyzed using three dedicated GCs. The first GC was equipped with a thermal conductivity detector and a Carbosphere packed column. It was used to quantify $\mathrm{O}_{2}$, $\mathrm{CO}$ and $\mathrm{CO}_{2}$. The second GC was equipped with a flame-ionization detector and a PlotQ capillary column. The flame-ionization detector was preceded by a methanizer to detect $\mathrm{CO}, \mathrm{CO}_{2}$ and formaldehyde with improved sensitivity. This GC was used to quantify molecules containing up to five carbon atoms. The third GC was equipped with a flame-ionization detector and a HP5-MS capillary column for quantifying molecules containing at least five carbon atoms. Response factors were determined by injecting calibration mixtures or using the effective carbon number method [18]. The exit of the reactor was connected with the aforementioned gas chromatographs through heated transfer lines kept at $423 \mathrm{~K}$ to limit condensation problems. The identification of the products has remained the same as in the previous work performed under stoichiometric conditions [10].

\subsection{Laser single-photon-ionization mass time-of-flight spectrometry}

Reaction products were also analyzed by a SPI-TOF-MS with single-photon ionization using VUV photons with a wavelength of $118 \mathrm{~nm}(10.6 \mathrm{eV}$ ) (see schematic diagram in Fig. S1 of the SM). The mass spectrometer covers a mass range of $\mathrm{m} / \mathrm{z}$ 10-2000 with mass resolution of 2000 and mass sensitivity of $100 \mathrm{ppm}$. Mole-fraction calculations were made using propene at $\mathrm{m} / \mathrm{z} 42$ as a reference (the value measured by gas chromatography at $650 \mathrm{~K}$ ) [15]. More details about mole fractions calculations can be found in the SM. Products were sampled using a heated quartz capillary tube (200$\mu \mathrm{m}$ diameter, $5-\mathrm{m}$ length, flow of 3-4 $\mathrm{mL} / \mathrm{min}$ ) directly inserted within the jet-stirred reactor. The whole sampling line was heated to $353 \mathrm{~K}$. This temperature was chosen carefully in order to preserve hydroperoxides and to maximize the related signal.

\section{4. cw-Cavity ring down spectroscopy}

A tubular-glass cw-CRDS cell (length: $76 \mathrm{~cm}$, diameter: $0.8 \mathrm{~cm}$ ), maintained at a pressure of $1.33 \mathrm{kPa}$ through pumping at both ends has been used to analyze formaldehyde, water, ethylene and hydrogen peroxide in the near infrared at wavelengths in the 6620-6644 cm-1 range (more details about experiments and calibration are given in the SM). As described previously [15,19], the cell was coupled to the JSR using a tubular quartz probe with a tip orifice of about $150 \mu \mathrm{m}$ diameter

The preceding procedure allowed checking the carbon atom balance within a deviation about $10 \%$, except for temperatures close to the maximum of low-temperature reactivity for which larger deviations were spotted (up to $20 \%$ at $625 \mathrm{~K}$ ), certainly due to the condensation of undetected large oxygenated products in GC and SPI-TOF-MS transfer lines. The uncertainty of mole fractions derived from MS measurements is usually estimated as $\pm 10 \%$ for major species, $\pm 25 \%$ for intermediates with known photo-ionization cross-sections (PICSs), and at least a factor of 2 for those with estimated PICSs. The uncertainty of mole fractions derived from CRDS measurements is usually estimated to be an average of $\pm 15 \%$. 


\section{Kinetic model development}

The 1-hexene oxidation model described hereafter, together with a glossary giving the linear notation corresponding to the name of each species used in the model, can be found in the SM under CHEMKIN format. All the related simulations have been performed using CHEMKIN PRO [20]. This model has been based on the model previously proposed by Bounaceur et al. [8], with some reaction pathways and kinetic data updated according to the recent literature.

\subsection{General description of the model of Bounaceur et al. [8]}

The model of Bounaceur et al. [8] was generated thanks to software EXGAS which is used to automatically generate models for the oxidation of components of fuels and biofuels [21]. A reaction mechanism generated by EXGAS is made up of three parts:

- $\mathrm{A} \mathrm{C}_{0}-\mathrm{C}_{2}$ reaction base, including all the reactions involving radicals or molecules containing less than three carbon atoms.

- A comprehensive primary mechanism including all the reactions of the molecular reactants, the initial organic compounds and oxygen, and of the derived free radicals.

- A lumped secondary mechanism, containing reactions consuming the molecular products of the primary mechanism which do not react in the reaction base.

Thermochemical data for molecules or radicals are automatically generated based on group and bond additivity methods proposed by Benson [22] using software THERGAS [23].

For alkene low-temperature oxidation, the generic reactions considered in the primary mechanism are:

- "Ene" and "retro-ene" molecular reactions.

- Fuel unimolecular initiations.

- Bimolecular initiations, with $\mathrm{O}_{2}$ or between two fuel molecules.

- Additions of $\mathrm{H}$ atoms and $\dot{\mathrm{O}} \mathrm{H}, \dot{\mathrm{CH}}_{3}$ and $\mathrm{HO}_{2}$ (with direct epoxydation) radicals to the fuel double bond.

- The abstraction of alkylic and allylic H-atoms from the fuel molecule.

- The reactions of alkylic, and allylic radicals with oxygen, including the formation of peroxy radicals from alkylic and allylic radicals, as well as the production of dienes and unreactive $\mathrm{HO}_{2}$ radicals.

- The radical (alkylic, allylic and peroxy) isomerizations involving a cyclic transition state including a ring with from 4 to 8 members.

- In the case of the peroxy radicals obtained by addition to $\mathrm{O}_{2}$ of radicals produced by addition of $\dot{\mathrm{OH}}$ to the double bond, this pathway includes the Waddington mechanism leading to aldehyde formation [10].

- Radical decompositions by $\beta$-scission or to produce cyclic ethers or branching agents.

- Allylic radical combinations, including especially the combination with $\mathrm{HO}_{2}$ radicals.

\subsection{Updated kinetics}

The list of the updated or added reactions is given in Table 1 and the detailed changes and their influence on simulations are described hereafter. Some comparisons are given using the JSR experimental results (stoichiometric mixtures with an initial fuel mole fraction set as 0.0095) which will be more thoroughly described in the next part of this text. In the figures below, the effects of the 
change of a given rate constant are obtained by changing this only rate constant in the present mechanism.

Table 1: Reactions updated or added.

\begin{tabular}{|c|c|}
\hline Reaction & Comments \\
\hline $\mathrm{H}_{2} \mathrm{O}_{2}(+\mathrm{M})<=>\dot{\mathrm{O}} \mathrm{H}+\dot{\mathrm{O}} \mathrm{H}(+\mathrm{M})$ & Rate constant taken from Troe [24] \\
\hline $\begin{array}{l}\text { Bimolecular initiation of } \mathrm{C}_{3}-\mathrm{C}_{4} \text { alkenes } \\
\text { with } \mathrm{O}_{2}\end{array}$ & Rate constant that proposed by Baulch et al. [25] for propene \\
\hline $\begin{array}{l}\text { Alkene+ }+\dot{\mathrm{O}} \mathrm{H}<=>\text { addition with adduct } \\
\text { formation }\end{array}$ & $\begin{array}{l}\text { Rate constant taken equal to that proposed by Zádor et al. [13] for } \\
\text { propene with a branching ratio } 1: 1\end{array}$ \\
\hline Alkene $+\dot{\mathrm{O}} \mathrm{H}=>$ allylic radical $+\mathrm{H}_{2} \mathrm{O}$ & $\begin{array}{l}\text { Rate constant taken equal to that proposed by Zádor et al. [13] for } \\
\text { propene }\end{array}$ \\
\hline Alkene+ÖH=>addition followed by & nstant taken equal to that proposed by Zádor et al. [13] \\
\hline decomposition & Erreur! Source du re \\
\hline Waddington mechanism & $\begin{array}{l}\text { Rate constants estimated using the values proposed by Lizardo- } \\
\text { Huerta et al. [14] }\end{array}$ \\
\hline Allylic radical $+\mathrm{HO}_{2}<=>$ products & Rate constant estimated from the work of Goldsmith et al. $[26,27]$ \\
\hline $\begin{array}{l}\mathrm{Hexene}+\mathrm{CH}_{3} \mathrm{O}=>\text { allyl radical }+ \\
\mathrm{CH}_{3} \mathrm{OH}\end{array}$ & Rate constant taken from Zhang et al. [28] \\
\hline$\alpha$-Hydroxyalkyl radical oxidation & $\begin{array}{l}\text { Rate constant estimated using the values proposed by da Silva et } \\
\text { al. [29] }\end{array}$ \\
\hline $\begin{array}{l}\mathrm{C}_{6} \text { keto- and aldo-hydroperoxides } \\
\text { decomposition }\end{array}$ & $\begin{array}{l}\text { Detailed description of the decomposition pathways and pressure } \\
\text { dependence taken into account }\end{array}$ \\
\hline
\end{tabular}

\subsubsection{Reactions of $C_{0}-C_{4}$ compounds}

In the current 1-hexene combustion mechanism, the rate coefficients for the thermal dissociation and the reverse recombination of hydrogen peroxide $\left(\mathrm{H}_{2} \mathrm{O}_{2}\right)$ are updated to the values recently reported by Troe [24]. As shown in Fig. 1, compared with the rate constants of Baulch et al. [30] which were used by Bounaceur et al. [8], the mechanism with altered rate constants gives a better prediction of the fuel reactivity at intermediate temperatures. With this update, the $\mathrm{H}_{2} \mathrm{O}_{2}$ mole fraction temperature profile remains in similar agreement with the JSR experimental results.
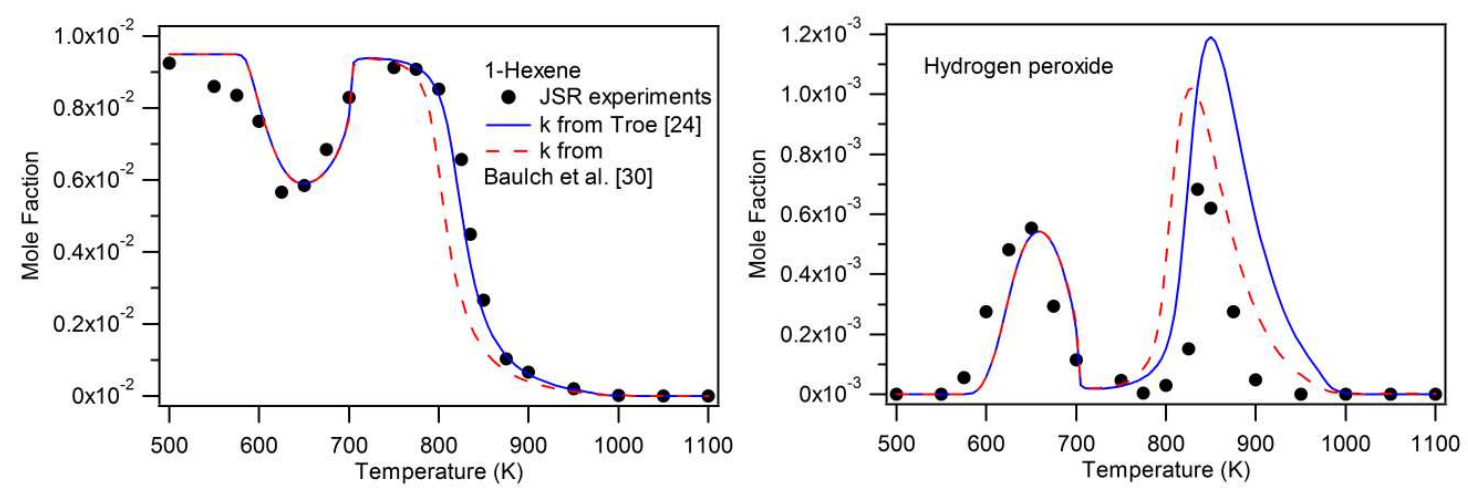

Figure 1: Effect of using the updated rate constants for $\mathrm{H}_{2} \mathrm{O}_{2}$ dissociation/recombination reactions [24] on predicted JSR species mole fraction temperature profiles. 
The rate constant for the bimolecular initiation of $\mathrm{C}_{3}-\mathrm{C}_{4}$ alkenes with $\mathrm{O}_{2}$ is adopted from the review by Baulch et al. [25] in the case of propene, resulting in a slight reduction of the fuel reactivity between 800 and $900 \mathrm{~K}$ compared to the model of Bounaceur et al. [8].

\subsubsection{Reactions of $\dot{O H}$ radicals with the fuel}

The reaction of $\dot{O} H$ radical with 1-hexene involves three possible channels: the additions with hydroxy adduct stabilization (see Figure S3 in the SM), the additions followed by decomposition (see Figure S3 in the SM), and $\mathrm{H}$-abstractions. The rate constants of these channels were taken from the theoretical work of Zádor et al. [13] on propene using the same pressure dependence. For the formation of the hydroxy adducts, we use a 1:1 branching ratio for the addition to the terminal or central carbon atom as suggested by Zádor et al. [13] and Kappler et al. [31]. In the case of 1-hexene, we consider that the additions followed by decomposition produce formaldehyde and pentyl radical or pentanal and methyl radical. Some rate comparisons between the present model and that of Bounaceur et al. [8] are plotted in Figure 2 and show large differences for allylic $\mathrm{H}$-abstractions and additions followed by decomposition. This explains why these changes have a significant effect on fuel consumption and product formation, mainly aldehyde production as also shown in Figure 2. The effect of the update of the rate constants for additions followed by decomposition is particularly impressive. Reducing the production of allylic radicals through allylic $\mathrm{H}$-abstractions reduce the reactivity because the reaction of allylic radicals with hydroperoxy radical promotes the low to intermediate temperature reactivity.

A concern about allylic $\mathrm{H}$-abstraction rate constant should nevertheless be mentioned: the values published by Zádor et al. [13] are for primary allylic $\mathrm{H}$-atoms, while secondary allylic $\mathrm{H}$-atoms are abstracted during 1-hexene oxidation. However, simulations using the value proposed by Vasu et al. [32] for the abstraction of secondary allylic $\mathrm{H}$-atoms leads to deteriorated predictions: the agreement is similar to that observed with the rate constant of Bounaceur et al. [8]. In addition, in their model of 2-butene oxidation, $\mathrm{Li}$ et al. [33] used for the abstraction of secondary allylic $\mathrm{H}$-atoms the values proposed by Vasu et al. [32] and divided by a factor of 2.6. This fitting leads to a rate constant close to that published by Zádor et al. [13] and used here.

\subsubsection{Waddington mechanism}

As proposed by Stark and Waddington [34], hydroxyperoxyradicals can react through a cyclic transition state to yield ${ }^{\circ} \mathrm{OH}$ radicals and aldehydes. One of these channels starting from 1-hexene is the following:

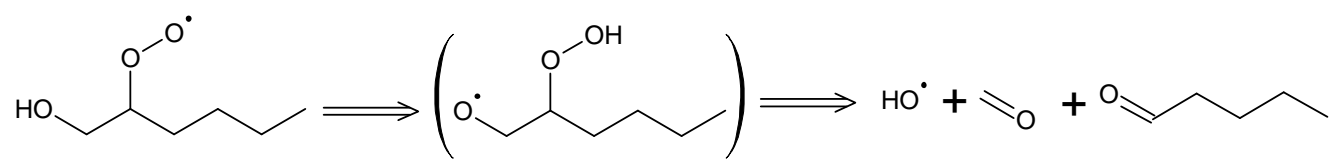

The other possible channel produces acetaldehyde and butanal via a two-step isomerization of the hydroxyradicals. In this study, the rate constants for the Waddington mechanism are adopted from the recent theoretical work of Lizardo-Huerta et al. [14]. Figure 3 displays a comparison between the rate constants of Bounaceur et al. [8] and that of Lizardo-Huerta et al. [14] for reaction (1). This figure also shows that the change of these rate constants has a slight effect on reactivity, but a more significant one on aldehyde formation. 

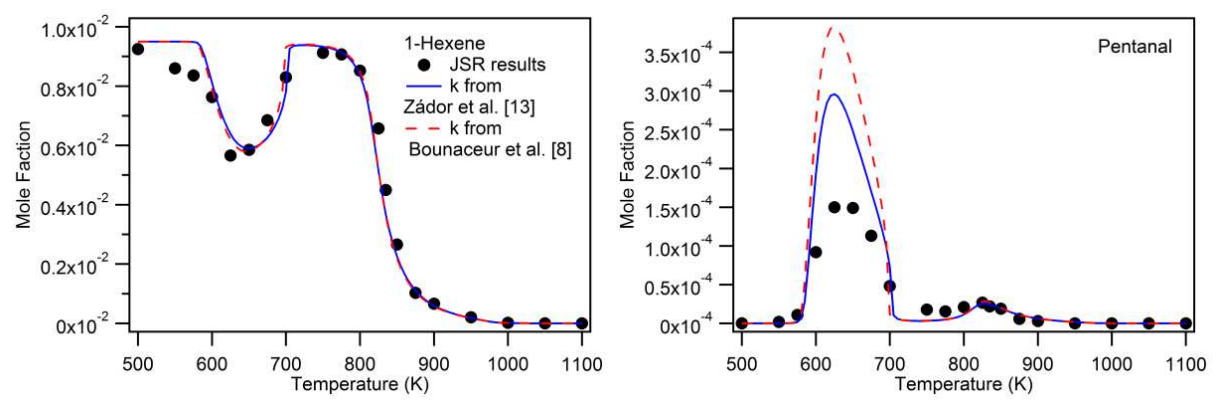

(a)
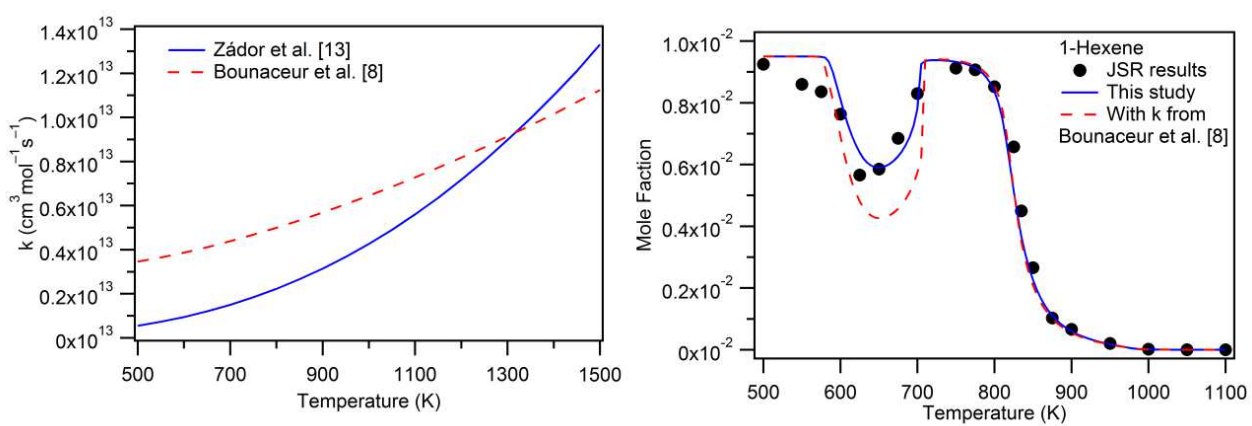

(b)
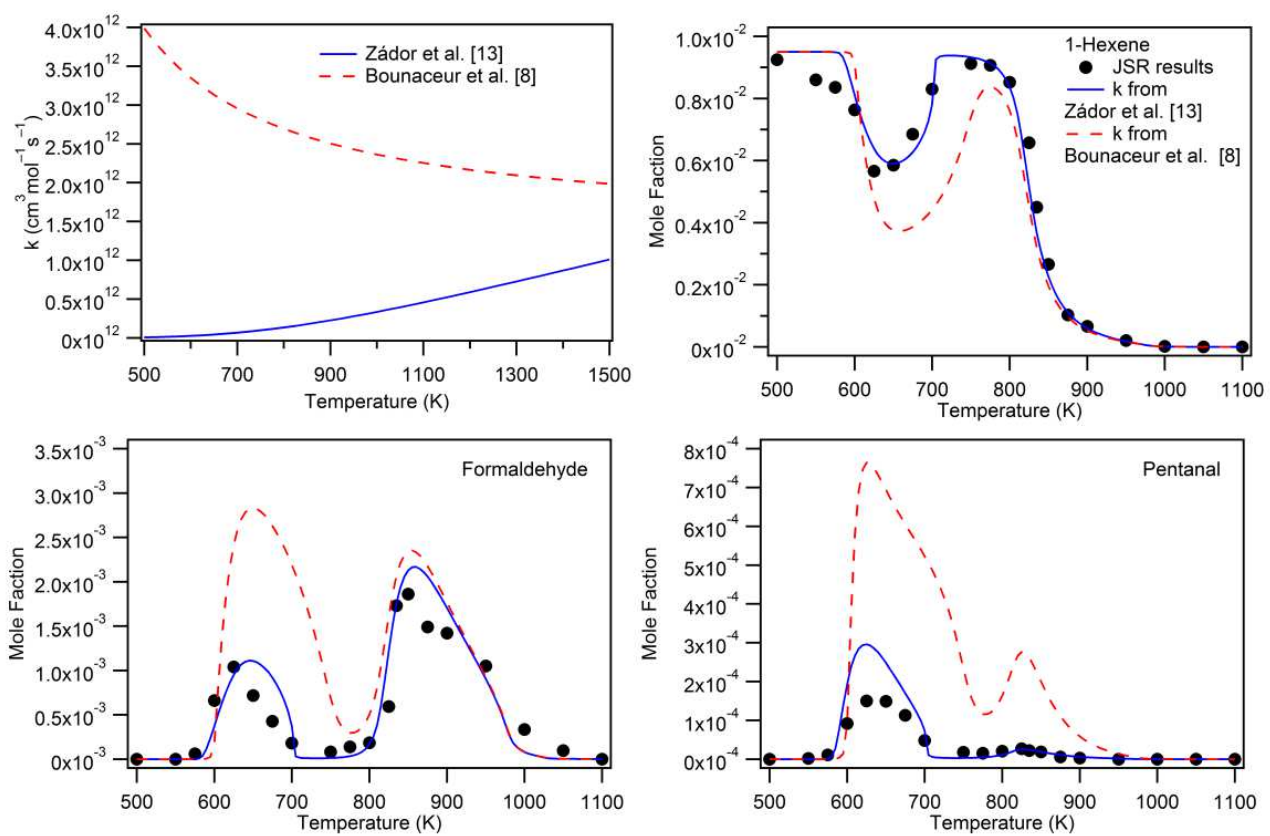

(c)

Figure 2: Rate constant comparison and effect of using the updated rate constants for the reactions of OH radicals with fuel on the predicted JSR species mole fraction temperature profiles: (a) additions with hydroxy adduct stabilization, (b) allylic $\mathrm{H}$-abstractions and (c) additions followed by decompositions (lines are rate constant or simulation values, symbols are experiments). 

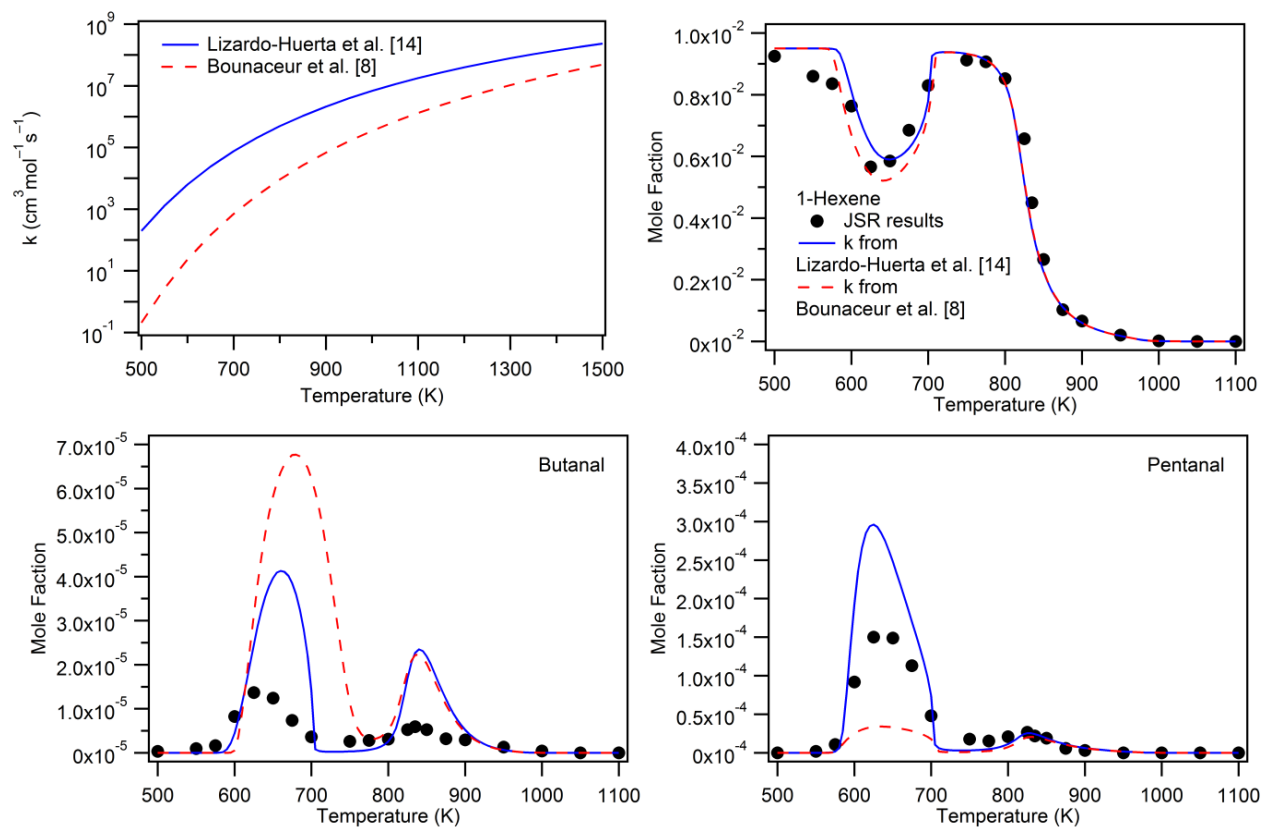

Figure 3: Rate constant comparison for reaction (1) and effect of using the updated rate constants for the Waddington mechanism.

\subsubsection{Combinations of allylic and $\mathrm{H}_{2}$ radicals}

Recently, Goldsmith et al. [26,27] theoretically investigated the reactions of the allylic radical with $\mathrm{HO}_{2}$, and detailed the rate constants of this reaction system. Burke et al. [35] demonstrated the importance of these reactions at low to intermediate temperatures in their propene mechanism, especially when modeling JSR results.

In the present study, we added these reactions, as well as the combinations of the allylic radicals deriving from 1-butene, 1-pentene and 1-hexene with $\mathrm{HO}_{2}$ radicals based on the pathways and kinetics proposed for propene. The pathways considered in the case of 1-hexene are shown in Figure 4a. Figure $4 \mathrm{~b}$ shows that this type of reactions plays an important role in the combustion of unsaturated hydrocarbons, which not only influences the fuel reactivity, but also acts as the main pathway leading to the formation of unsaturated aldehydes. The effect on the reactivity is due to the conversion of the relatively unreactive $\mathrm{HO}_{2}$ into the very reactive $\dot{\mathrm{OH}}$ radicals.

\subsubsection{Hexene $+\mathrm{CH}_{3} \dot{\mathrm{O}}=>$ allylic radical $+\mathrm{CH}_{3} \mathrm{OH}$}

As this reaction produces allylic radicals, which combine with $\mathrm{HO}_{2}$ radicals, it should have a notable impact on the fuel reactivity. The rate constant adopted in this study is from the recent hexane mechanism of Zhang et al. [28]. As it can be seen in Figure 5, the rate constant used by Bounaceur et al. [8] for this reaction was around 3-6 order of magnitude faster than that used in the present study, thereby producing many more allylic radicals, which subsequently react with $\mathrm{HO}_{2}$ accelerating the fuel consumption. However, it will be shown further in the text that this update also massively decreases the production of methanol. 

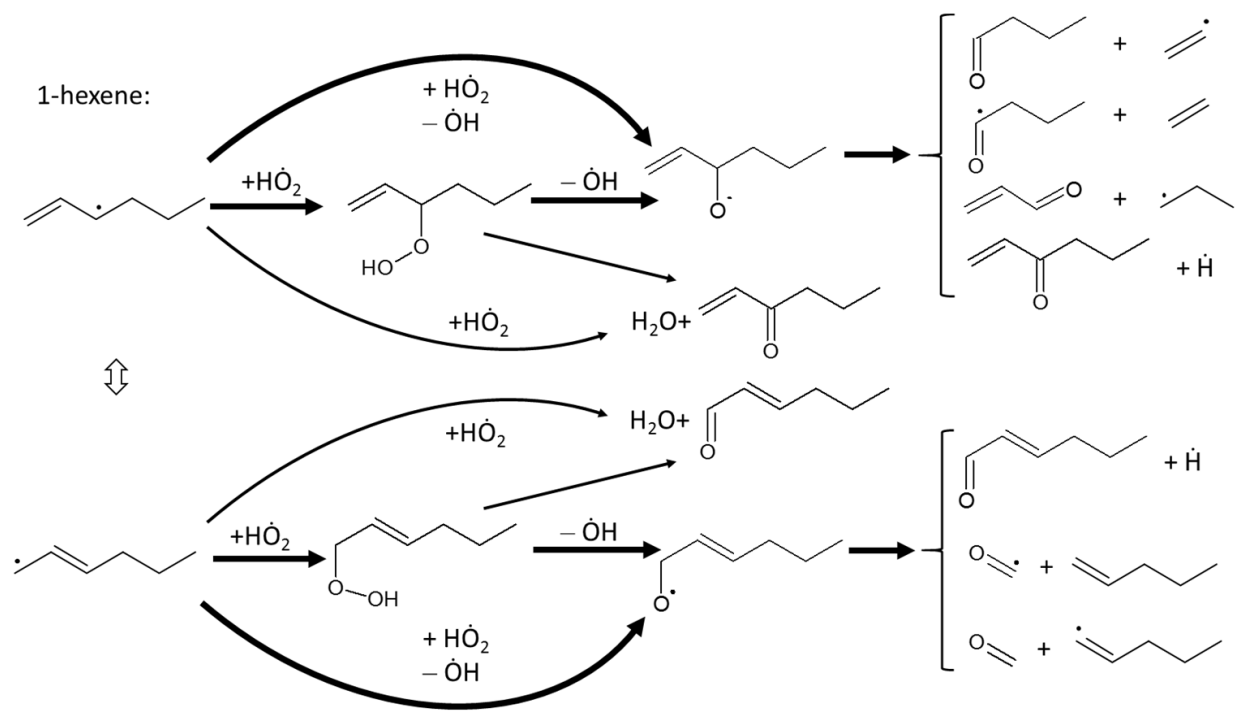

(a)
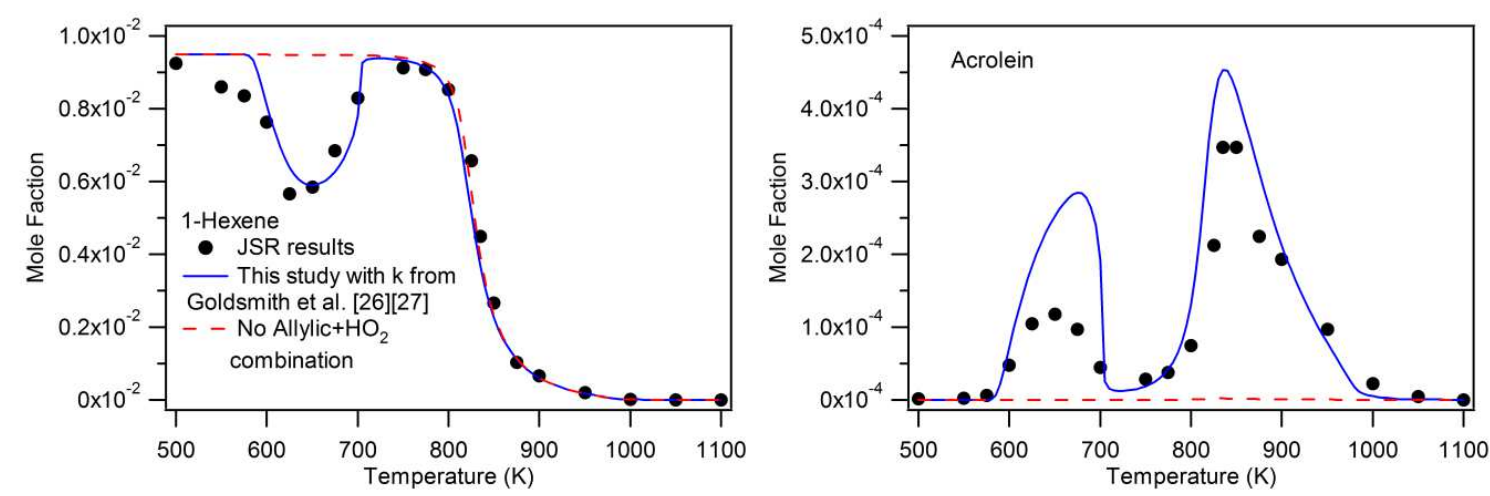

(b)

Figure 4: Update for the combination of $\mathrm{C}_{6}$ allylic with $\mathrm{HO}_{2}$ radicals: (a) added pathways, and (b) effect of using these updated pathways and kinetics for $\mathrm{C}_{3}-\mathrm{C}_{6}$ allylic radicals.
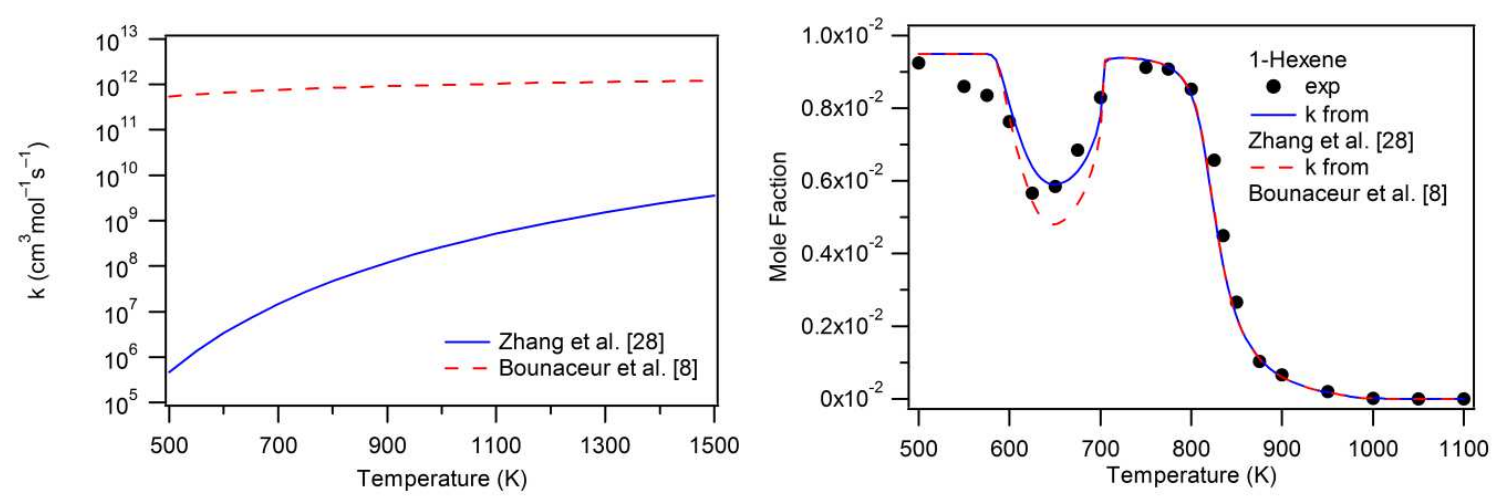

Figure 5: Rate constant comparison for the reaction Hexene $+\mathrm{CH}_{3} \dot{\mathrm{O}}=>$ allylic radical $+\mathrm{CH}_{3} \mathrm{OH}$ and effect of using the updated rate constants. 


\subsection{6. $\alpha$-Hydroxyalkyl radical oxidations}

Due to the low reactivity of HÖ2 radicals below $800 \mathrm{~K}$, the $\alpha$-hydroxyalkyl radical oxidation (i.e. the reaction with oxygen yielding aldehydes or ketones and HÖ2 radicals) has an inhibiting effect on fuel consumption. This reaction was theoretically studied by Zádor et al. [36] and da Silva et al. [29]. These last authors published a rate constant for this reaction which was widely accepted in alcohol combustion chemistry [37], and which was then also adopted in this study. A rate comparison between the present model and that of Bounaceur et al. [8] is plotted in Fig. 6a and shows an impressive difference. The inhibiting effect of this reaction is evidently indicated in Fig. 6b, which demonstrates that this type of reaction needs to be taken into account in mechanism development for unsaturated fuels. The reason is that the addition of $\mathrm{OH}$ to the double bond is a major consumption pathway at low to intermediate temperatures [7] ; [8], and the hydroxy adduct can then isomerize via a two-step pathway to $\alpha$-hydroxyalkyl radicals, which can easily react to yield aldehydes/ketones and the unreactive HÖ2 radicals (see reaction (2)) instead of adding to 02 and leading to branching steps.
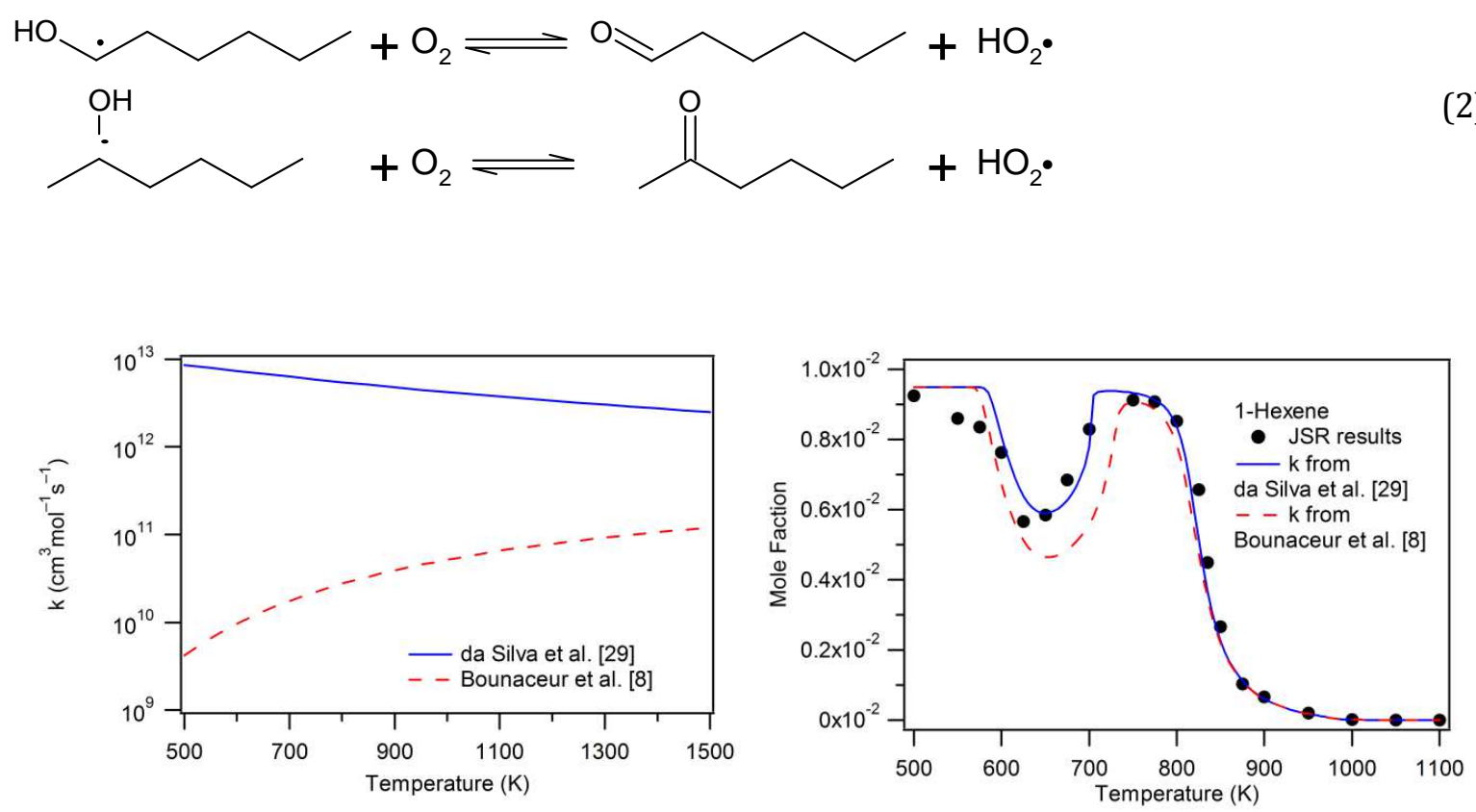

Figure 6: Rate constant comparison for the $\alpha$-hydroxyalkyl radical oxidations and effect of using the updated rate constants.

\subsection{7. $C_{6}$ keto- and aldo-hydroperoxides decomposition}

As usually made during EXGAS generation to limit model sizes [21], in the model of Bounaceur et al. [8], the $\mathrm{C}_{6}$ keto- and aldo-hydroperoxides were lumped into one virtual species. Since their decompositions have a significant contribution to the production of aldehydes, in the present study, the saturated $\mathrm{C}_{6}$ keto- and aldo-hydroperoxides were considered individually as illustrated in Figure $7 \mathrm{a}$ for one of them. As shown in Figure $7 \mathrm{~b}$, this more detailed description of saturated $\mathrm{C}_{6}$ keto- and aldo-hydroperoxide decompositions not only has a small influence on the fuel reactivity at low temperature, but also influences significantly the production of propanal in case of 1-hexene. 


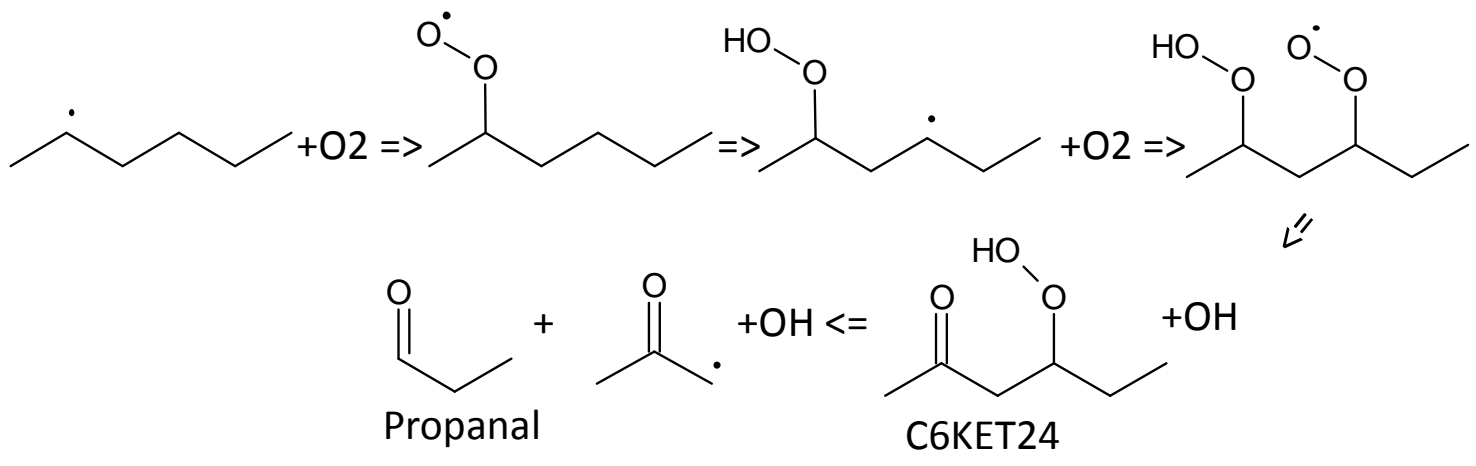

(a)
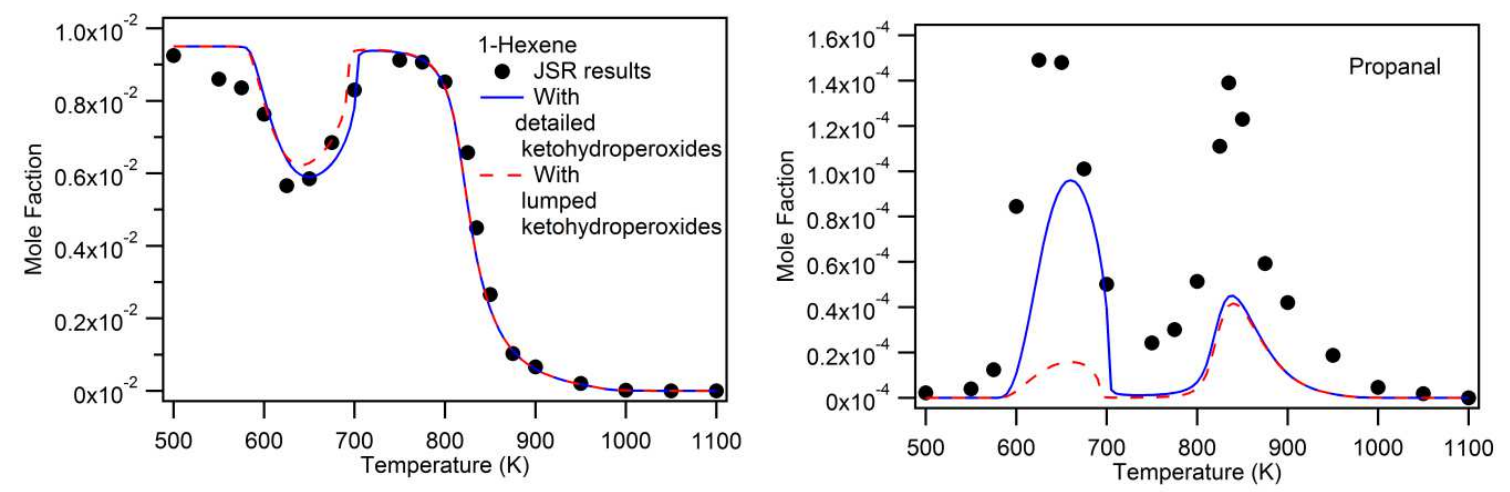

(b)

Figure 7: More detailed $\mathrm{C}_{6}$ keto- and aldo-hydroperoxides decompositions: (a) example of hydroperoxide identification and consumption pathway, and (b) effect of using these more detailed pathways.

Concerning the rate constants of the decomposition of large hydroperoxides, the original rate expression used by Bounaceur et al. [8] was $1.5 \times 10^{16} \exp (-42,000 \mathrm{cal} / \mathrm{RT}) \mathrm{s}^{-1}$, which is that adopted by Curran et al. [38] in their iso-octane mechanism and close to the value experimentally determined by Sahetchian et al. [39]. With this rate constant, the present model leads to a good prediction of the ignition delay times measured at high pressure in a rapid compression machine [4]. However the peak of the production of large hydroperoxides or ketohydroperoxides in JSR experiments at atmospheric pressure is shifted by about $30 \mathrm{~K}$ compared to experiment data.

As displayed in Figure 8, recent theoretical studies by Goldsmith et al. [26,40] show that there is a pressure dependence of the rate constants of the decomposition of hydroperoxides and ketohydroperoxides. To give an idea of the fall-off effect, according to Goldsmith et al. [40], the rate constant of the decomposition of ketohydroperoxides is increased by a factor of 4 when pressure is varied from 0.1 to $10 \mathrm{~atm}$ of nitrogen. Therefore, we have used for the decomposition of all $\mathrm{C}_{3}+$ saturated hydroperoxides: at $1 \mathrm{~atm}$, the rate expression of $4.0 \times 10^{15} \exp (-42,900 \mathrm{cal} / \mathrm{RT}) \mathrm{s}^{-1}$, which was proposed by the review of Baulch et al. [25] for $\mathrm{C}_{2} \mathrm{H}_{5} \mathrm{OOH}$ decomposition, and, at $10 \mathrm{~atm}$, the original rate expression of $1.5 \times 10^{16} \exp (-42,000 \mathrm{cal} / \mathrm{RT}) \mathrm{s}^{-1}$. With such a pressure dependence, as shown hereafter, the model can both predict the rapid compression machine data [4], and the evolutions of large hydroperoxide mole fraction versus temperature measured in JSR. In the former case, the location of the maximum is extremely sensitive to this rate constant as shown in Figure 9. 


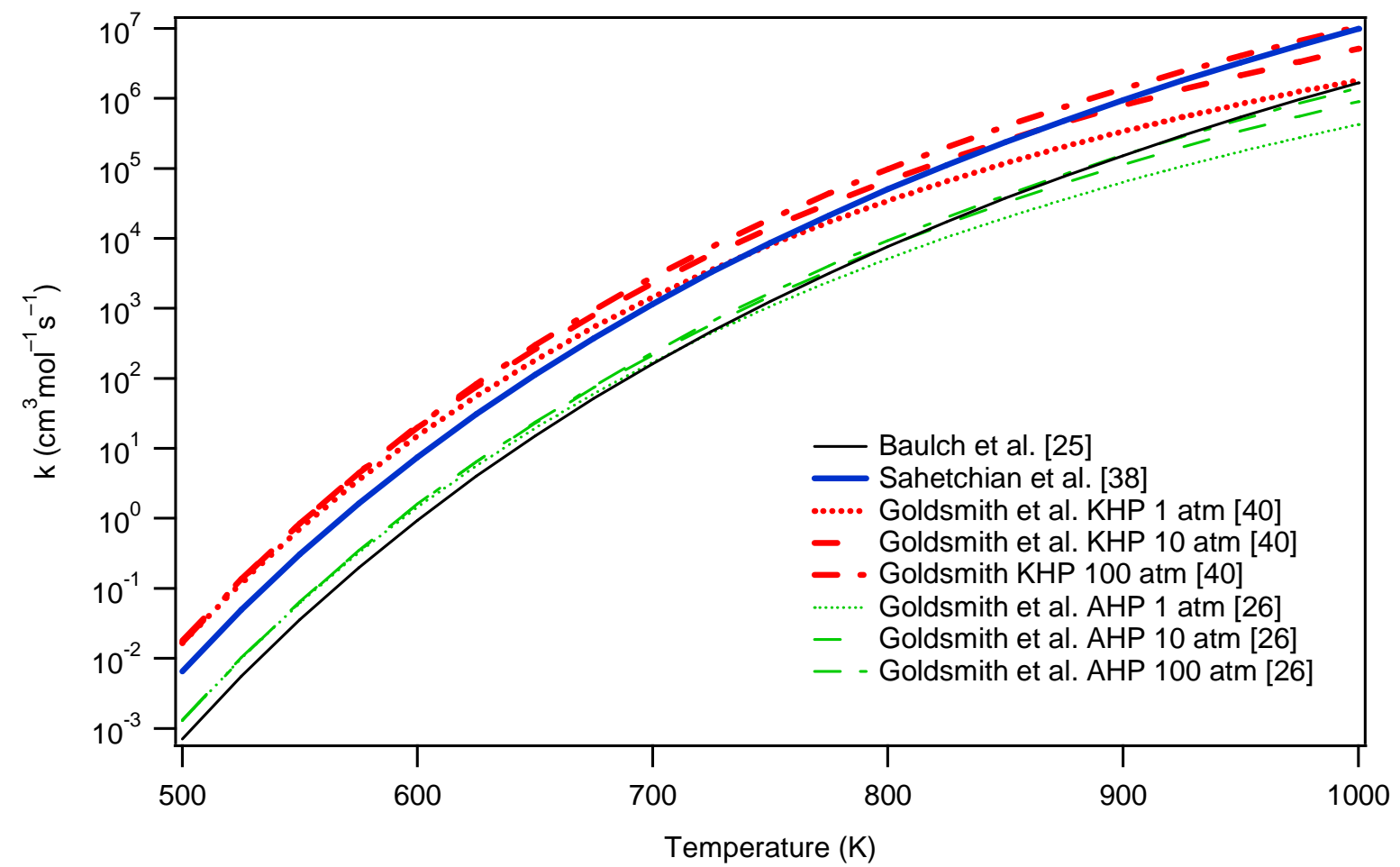

Figure 8: Evolution of the rate constant for hydroperoxide decomposition as a function of temperature and pressure according to various literature studies (KHP: ketohydroperoxides, AHP: allyl hydroperoxides).

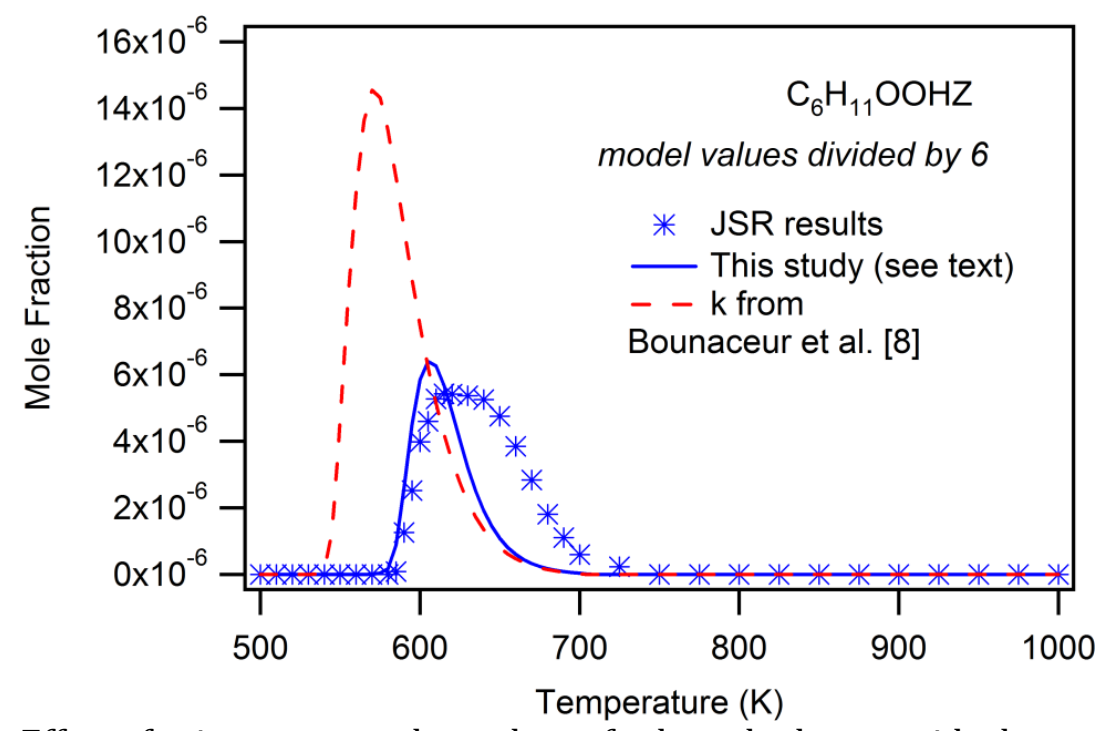

Figure 9: Effect of using pressure dependence for large hydroperoxide decompositions. 


\subsection{Simulations of previous literature data}

The current model was used to predict the cool flame and auto-ignition delay times observed by Vanhove et al. [4] in a rapid compression engine for 1-hexene $/ \mathrm{O}_{2} / \mathrm{Ar} / \mathrm{N}_{2} / \mathrm{CO}_{2}$ mixtures at temperatures after compression (Tc) ranging from 615 to $850 \mathrm{~K}$.
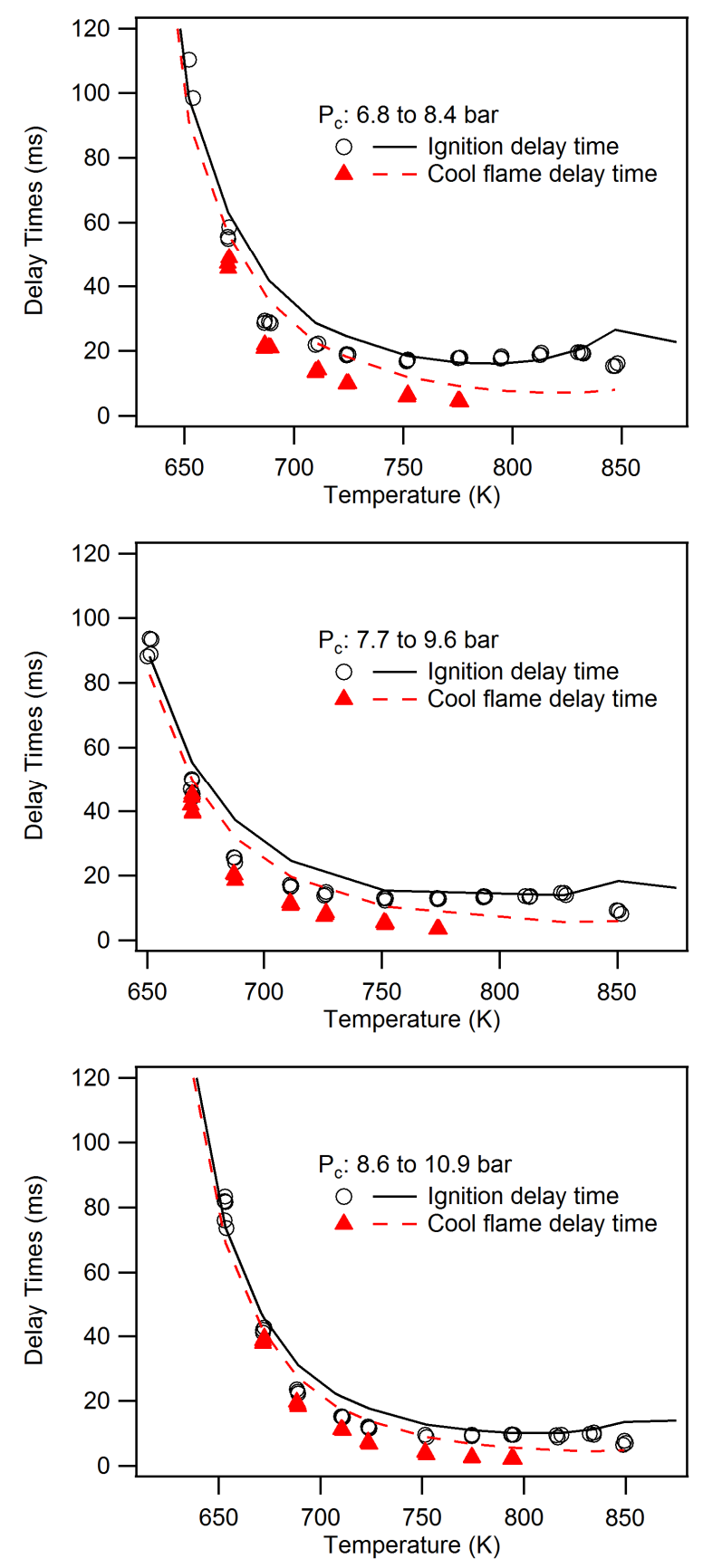

Figure 10: Ignition and cool flame delay times in a rapid compression machine (stoichiometric mixtures in air, Pc: from 6.8 to 8.4 bar, from 7.7 to 9.6 bar, from 8.6 to 10.9 bar [4]). Symbols are experiments and lines simulations. 
The experiments were conducted under three initial pressures leading to pressures (Pc) after compression ranging from 6.8 to 8.4 bar, from 7.7 to 9.6 bar, from 8.6 to 10.9 bar. The simulation conditions were assumed as constant volume with no heat loss since reactive pressure traces are not available. The first peak of the $\mathrm{OH}$ emission trace is taken as the cool flame delay time, and the second peak of the $\mathrm{OH}$ emission trace is taken as the ignition delay time. However, at high temperatures, there is only one peak which is the ignition delay time. As is shown in Figure 10, satisfactory agreement between the simulation and experimental results has been obtained for both the auto-ignition and cool flame delay times over the whole pressure range studied.

The model was also used to reproduce results obtained for high temperature oxidation: the JSR results at 10 bar of Yahyaoui et al. [41] and the shock tube data of Yahyaoui et al. [41] and Mehl et al. [9]. As shown in the SM, the model also gave reasonable predictions under these conditions.

\section{JSR experimental results and comparison with simulations using the new model}

We show hereafter the results obtained by JSR for the equivalence ratios $(\phi)$ of 2.0, 1 and 0.5 (with an initial fuel mole fraction set as 0.01 , present study and results by Battin Leclerc et al. [10]) and we compare them to simulations performed using the previously described model (Figs. 11-16). For the clarity of the following figures, when measurements were possible using several experimental techniques previously described, the experimental data obtained using all techniques are only shown in the case of stoichiometric conditions. The experimental data at the three $\phi$ values are only plotted for what we considered as the most accurate analytical technique for the given species. However the mole fractions obtained for all performed measurements can be found in a spreadsheet in the SM. Error bars are given for stoichiometric conditions for all compounds except from organic hydroperoxides.

\subsection{Reactant and main products mole fraction profiles}

Figure 11 shows the experimental and simulated evolutions of the mole fractions of fuel, oxygen, carbon oxides, water, hydrogen peroxide, methane and methanol, as a function of temperature between 500 and $1100 \mathrm{~K}$. The present experimental measurements indicate that the significant NTC behavior observed under stoichiometric conditions [10] is confirmed at $\phi=0.5$ and 2 . Below $800 \mathrm{~K}$, a richness decrease leads to a notable increase of the reactivity. The influence of equivalence ratio is more limited at higher temperatures. A decrease in $\phi$ values promotes the formation of oxygenated products whatever the temperature.

The model reproduces well the reactant consumption under every studied condition, except from an overprediction of the fuel consumption between 680 and $780 \mathrm{~K}$ in rich mixtures and an underprediction between 800 and $850 \mathrm{~K}$ in lean mixtures. The formation of carbon oxides and methane is well captured by the model. This is also the case for water under rich conditions, with more deviation in lean and stoichiometric conditions. The large error bars indicated above $900 \mathrm{~K}$ are due to saturation of the CRDS signal making the experimental measurements less accurate. The evolution of the $\mathrm{H}_{2} \mathrm{O}_{2}$ mole fraction as a function of temperature is well simulated under stoichiometric conditions, with more deviations under rich and lean conditions. As explained previously, the production of methanol is significantly underestimated. The co-elution of methanol and acetaldehyde may reduce the measurement accuracy. 

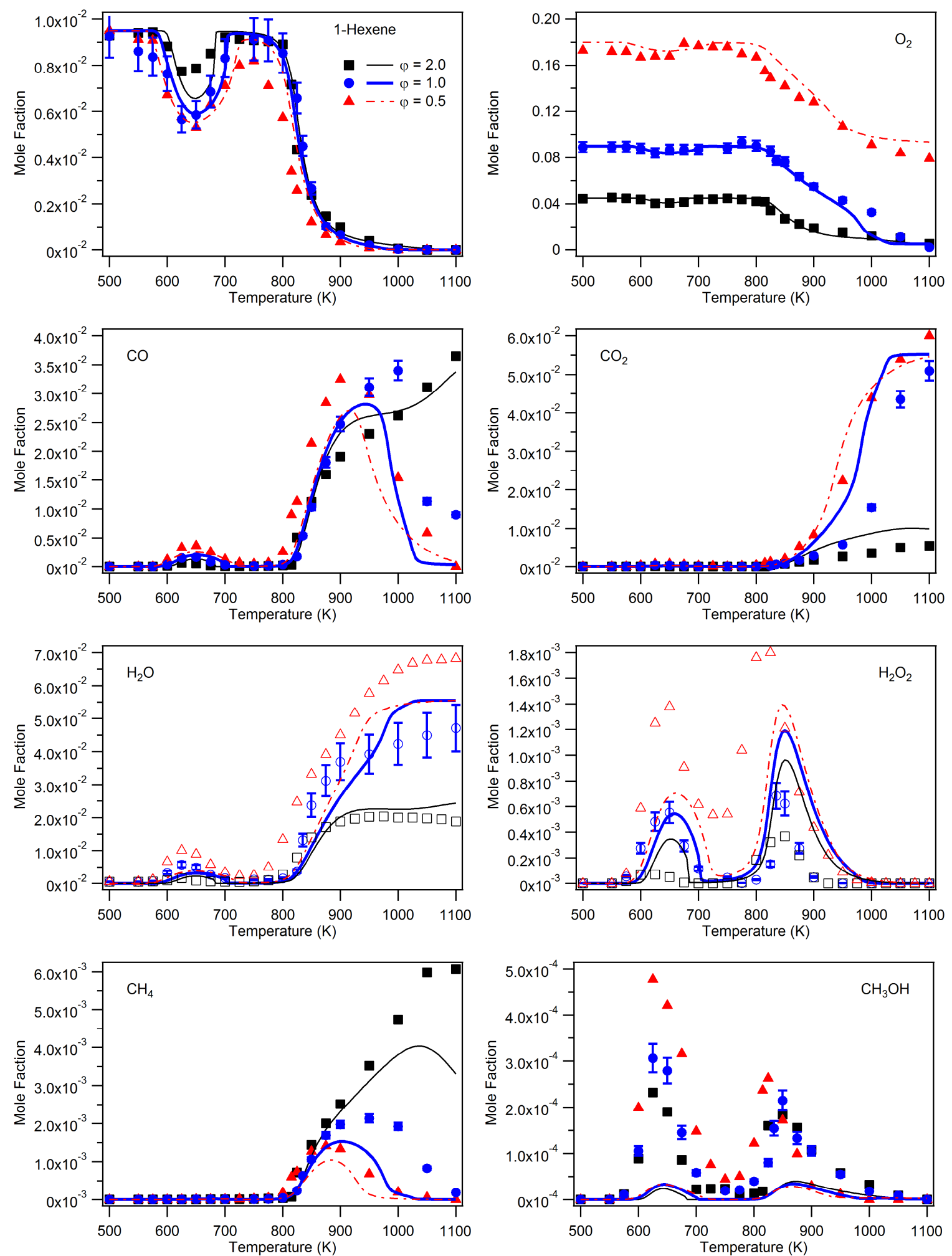

Figure 11: Mole fraction profiles of reactants and $\mathrm{C} 0-\mathrm{C} 1$ reaction products for 1-hexene oxidation in a jet-stirred reactor at $\varphi=0.5,1.0$ and $2.0, \mathrm{P}=106.7 \mathrm{kPa}, \tau=2 \mathrm{~s}$. Full symbols are GC experiments, open symbols CRDS experiments and lines simulations. 

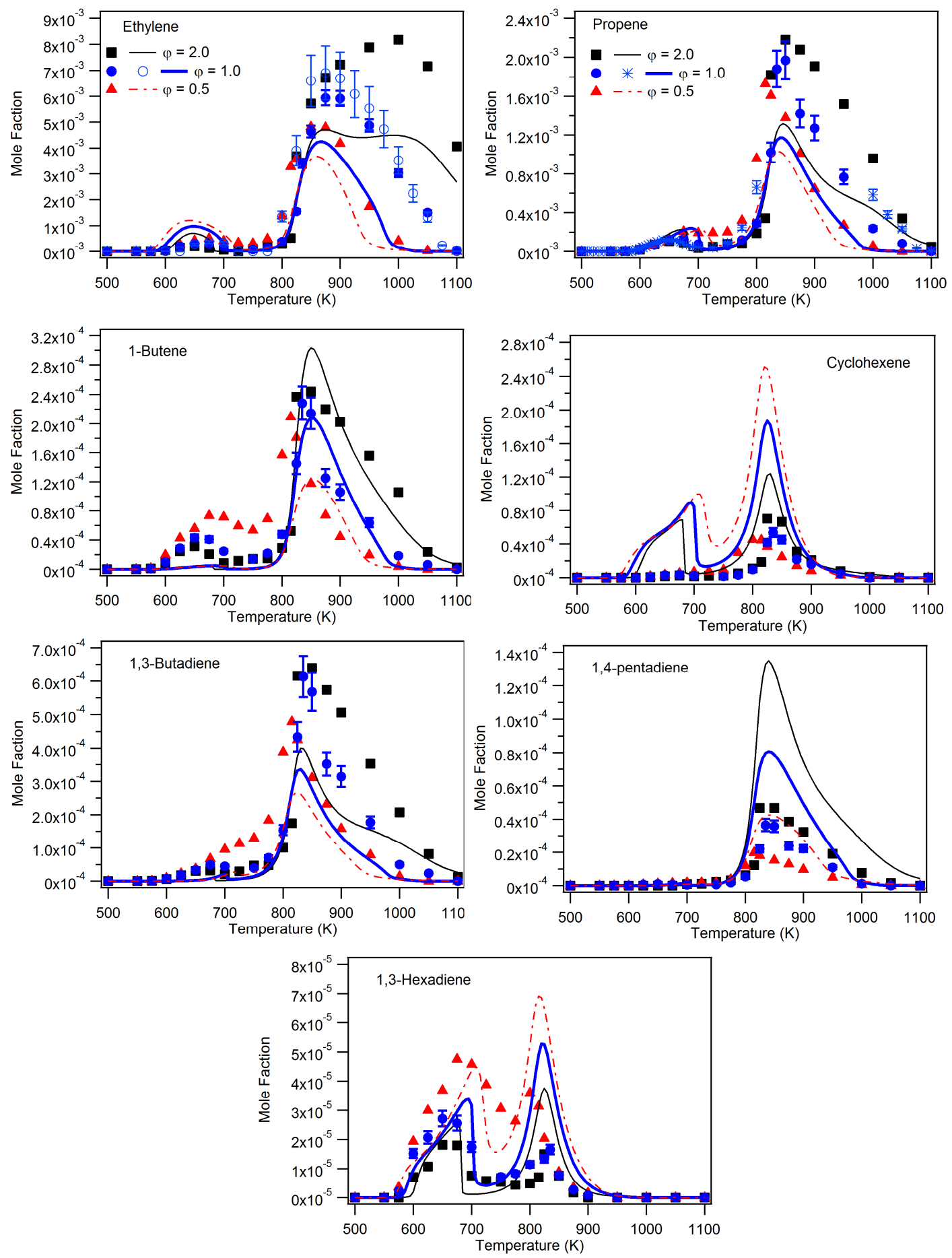

Figure 12: Mole fraction profiles of alkenes, cycloalkenes and dienes for 1-hexene oxidation in a jetstirred reactor at $\varphi=0.5,1.0$ and $2.0, \mathrm{P}=106.7 \mathrm{kPa}, \tau=2 \mathrm{~s}$. Full symbols are GC experiments, open symbols CRDS experiments, star symbols SPI-TOF-MS experiments and lines simulations. 

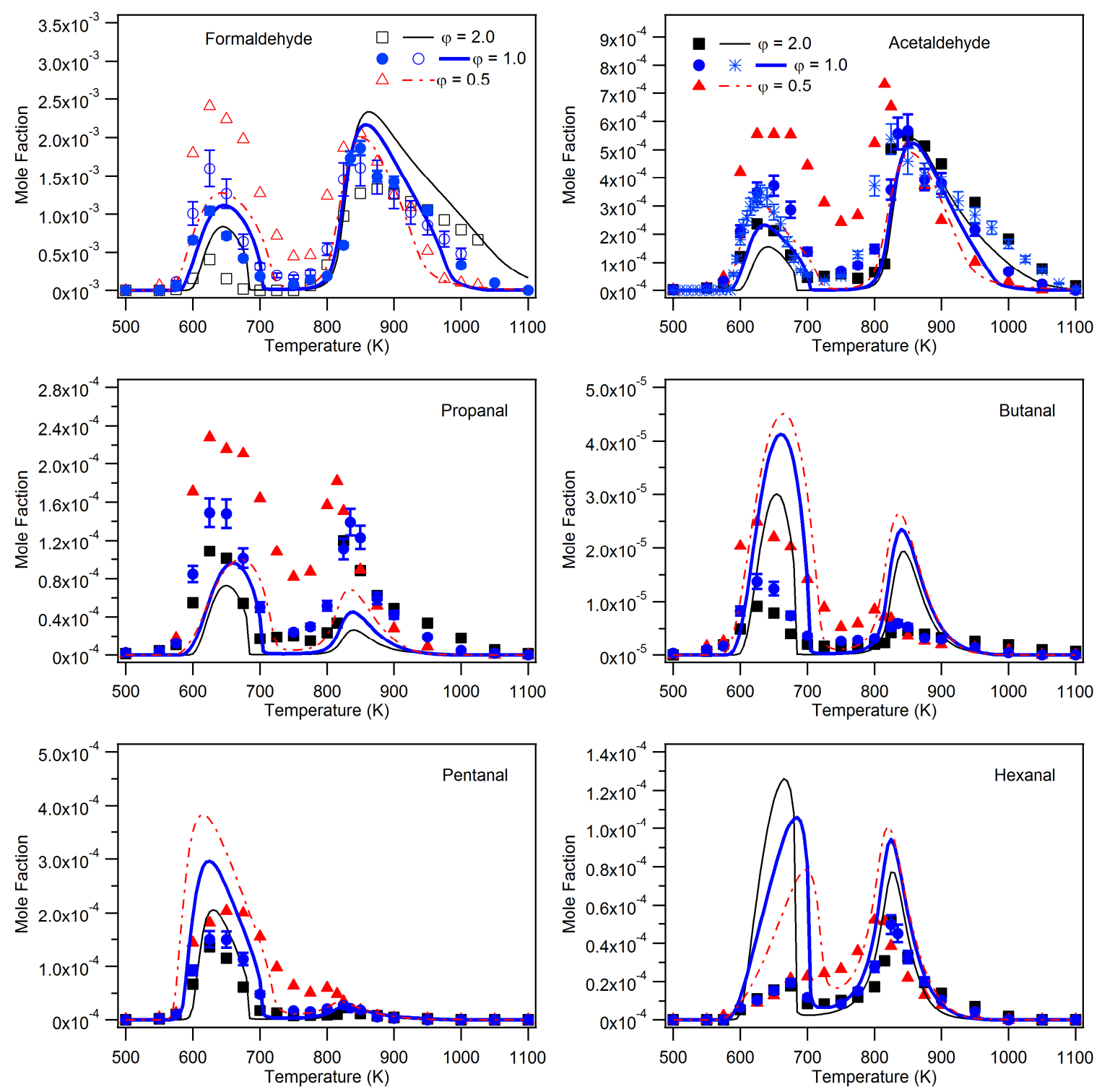

Figure 13: Mole fraction profiles of saturated aldehydes for 1-hexene oxidation in a jet-stirred reactor at $\varphi=0.5,1.0$ and $2.0, \mathrm{P}=106.7 \mathrm{kPa}, \tau=2 \mathrm{~s}$. Full symbols are GC experiments, open symbols CRDS experiments, star symbols SPI-TOF-MS experiments and lines simulations.

\subsection{Unsaturated hydrocarbon mole fraction profiles}

Figure 12 displays the experimental and simulated evolutions of the mole fraction of ethylene, propene, 1-butene, 1,3-butadiene, cyclohexene, 1,4-pentadiene, 1,3-hexadiene, as a function of temperature. $\mathrm{C}_{2}-\mathrm{C}_{3}$ alkenes are the most abundant of these products, and 1,3-hexadiene the least abundant. It was possible to measure ethylene mole fraction using both GC and CRDS with a good agreement between both techniques. It was also possible to measure propene mole fraction using both GC and SPI-TOF-MS with a good agreement between both techniques. However, the SPI-TOF-MS propene signal is saturated between 800 and $1000 \mathrm{~K}$ making the quantification not possible in this temperature range. A decrease in $\phi$ values enhances the formation of unsaturated hydrocarbons 
below $800 \mathrm{~K}$, but reduces it at higher temperatures apart from for 1,3-hexadiene which is mostly produced from the oxidation of alkenyl radicals yielded by $\mathrm{H}$-abstractions from fuel.

The formation of all these species is globally well captured by the model (within a factor of 2) whatever $\phi$, except from cyclohexene which is notably overpredicted, especially below $800 \mathrm{~K}$. The largest other deviations are mostly observed for ethylene, propene, 1,3-butadiene, and 1,4-pentadiene in rich mixtures above $900 \mathrm{~K}$.

\subsection{Aldehydes mole fraction profiles}

Figures 13 and 14 show the experimental and simulated evolutions of the mole fractions of saturated and unsaturated aldehydes, respectively, as a function of temperature.
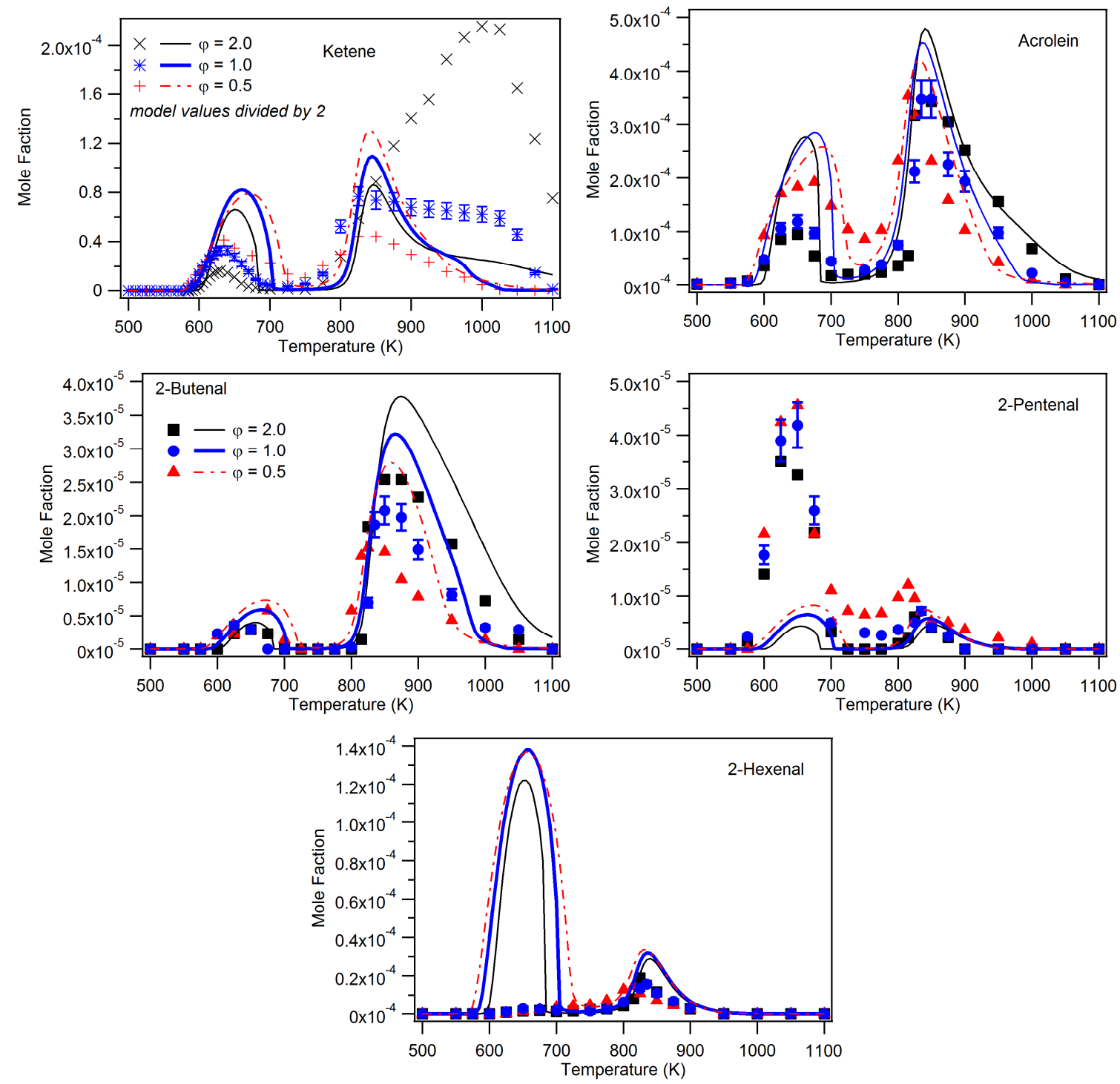

Figure 14: Mole fraction profiles of unsaturated aldehydes for 1-hexene oxidation in a jet-stirred reactor at $\varphi=0.5,1.0$ and 2.0, $\mathrm{P}=106.7 \mathrm{kPa}, \tau=2 \mathrm{~s}$. Full symbols are GC experiments, cross or star symbols SPI-TOF-MS experiments and lines simulations. 
Figure 14 displays the mole fractions of ketene, which were obtained by SPI-TOF-MS and were not quantified by Battin Leclerc et al. [10]. The most abundant saturated aldehydes are formaldehyde, acetaldehyde, propanal and pentanal. The most abundant unsaturated aldehydes are acrolein and ketene. For all saturated aldehydes, a decrease in $\phi$ values promotes the formation of oxygenated products whatever the temperature.

The formation of all saturated aldehydes, except from butanal above $800 \mathrm{~K}$ and hexanal below $800 \mathrm{~K}$, as well as acrolein and 2-butenal, is predicted by the model within a factor of around 2 whatever the equivalence ratio. Significantly larger deviations can be spotted for the other species, especially below $800 \mathrm{~K}$.

\subsection{Cyclic ether mole fraction profiles}

Figure 15 displays the experimental and simulated evolutions as a function of temperature of the mole fraction of $\mathrm{C}_{6}$ cyclic ethers, for which the most abundant ones are $\mathrm{C}_{6}$ oxiranes (the sum of 2,3diethyloxirane and butyloxirane is plotted in Figure 14 ) and the $\mathrm{C}_{6}$ tetrahydrofurans bearing an alcohol function. 2,5-Dimethyltetrahydrofuran and unsaturated $\mathrm{C}_{6}$ cyclic ethers are formed in lower amounts. The distribution of the isomers of unsaturated $C_{6}$ cyclic ethers cannot be known from gas chromatography-mass spectrometry analyses. In the model, 2-methyl-5methylidenetetrahydrofuran, 2-ethyl-2,5-dihydrofuran, and 2-ethyl-2,3-dihydrofuran have been considered. The mole fraction profiles are well simulated by the model for $\mathrm{C}_{6}$ oxiranes and hydroxyl $\mathrm{C}_{6}$ cyclic ethers, but more deviations can be noticed for the other types of ethers, which are highly overestimated below $800 \mathrm{~K}$.
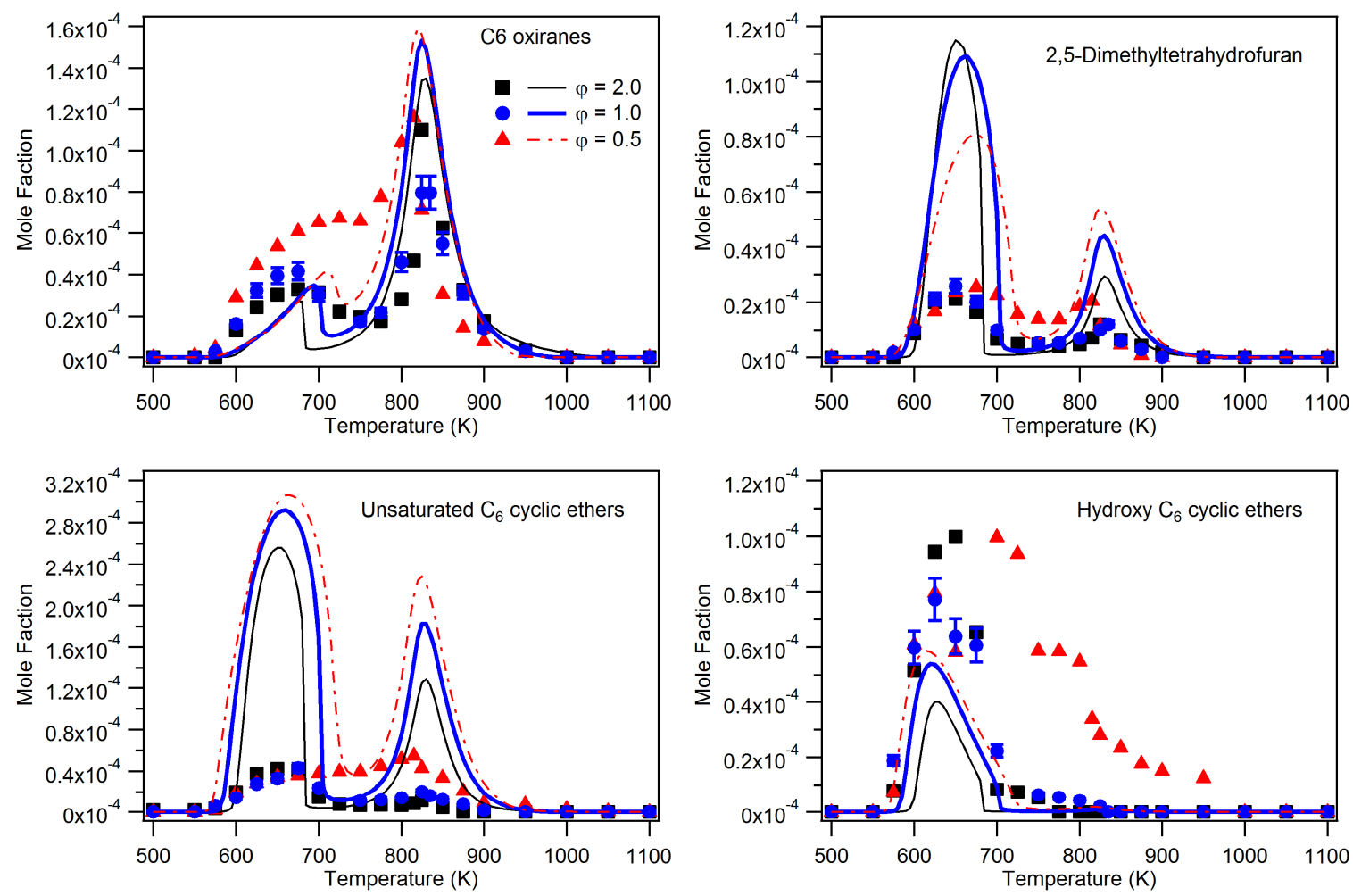

Figure 15: Mole fraction profiles of cyclic ethers for 1-hexene oxidation in a jet-stirred reactor at $\varphi=$ $0.5,1.0$ and $2.0, \mathrm{P}=106.7 \mathrm{kPa}, \tau=2 \mathrm{~s}$. Full symbols are GC experiments and lines simulations. 


\subsection{Hydroperoxide mole fraction profiles}

For hydroperoxides, new measurements have been performed using SPI-TOF-MS. Figure 17 shows the mass spectrum obtained at $600 \mathrm{~K}$ : the $\mathrm{m} / \mathrm{z}$ corresponding to hydroperoxides $(48,62,74,76,116$ and 130) can be well spotted. These hydroperoxides are $\mathrm{CH}_{3} \mathrm{OOH}, \mathrm{C}_{2} \mathrm{H}_{5} \mathrm{OOH}, \mathrm{C}_{3} \mathrm{H}_{5} \mathrm{OOH}, \mathrm{C}_{3} \mathrm{H}_{7} \mathrm{OOH}$, $\mathrm{C}_{6} \mathrm{H}_{11} \mathrm{OOH}$ and $\mathrm{C}_{6}$ unsaturated ketohydroperoxides, respectively. The $\mathrm{m} / \mathrm{z}=130$, for $\mathrm{C}_{6}$ unsaturated ketohydroperoxides, corresponds to an extremely low signal. The distribution of the isomers of $\mathrm{C}_{3}-\mathrm{C}_{6}$ hydroperoxides cannot be known from SPI-TOF-MS analyses.
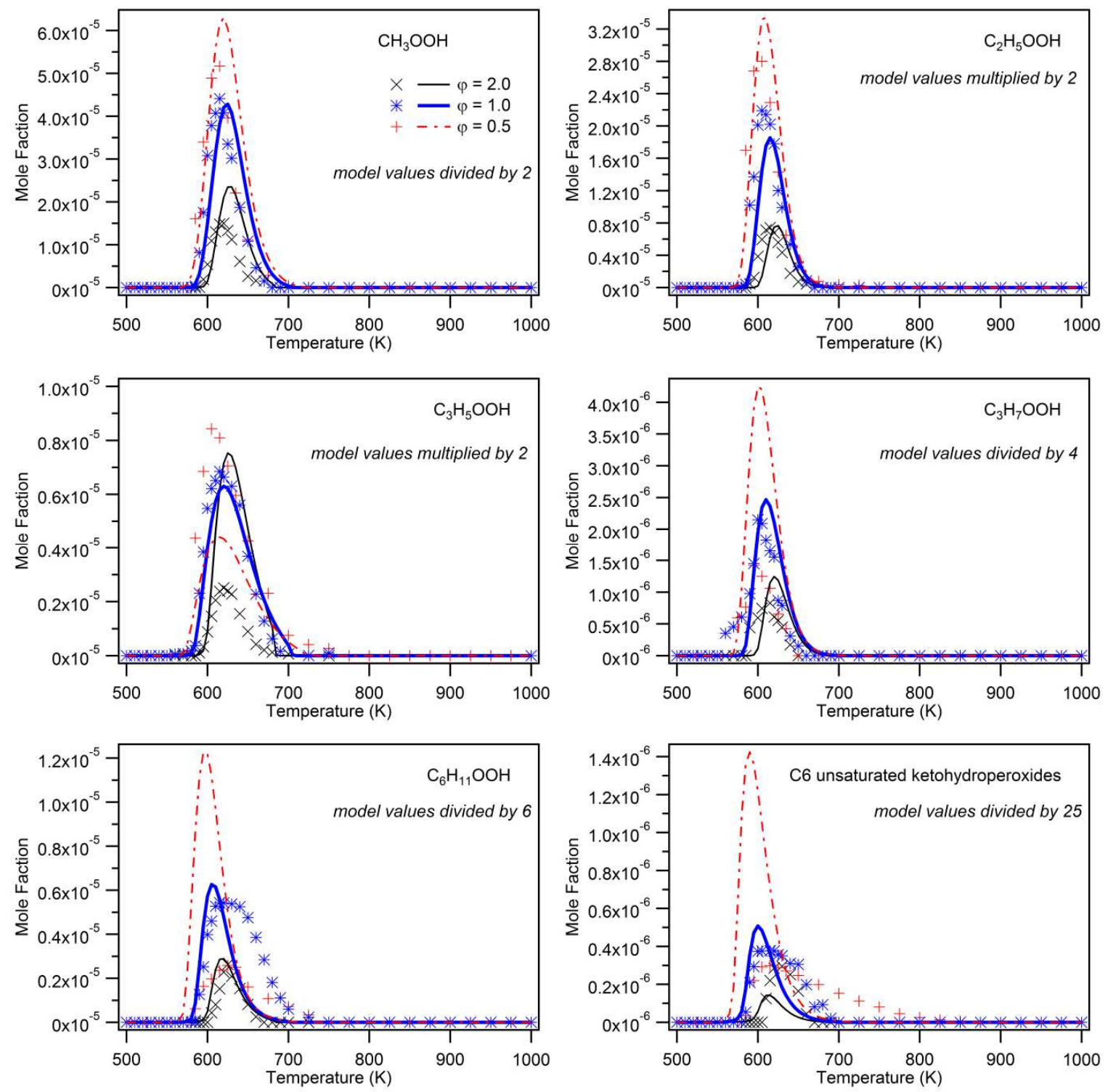

Figure 16: Mole fraction profiles of hydroperoxides for 1-hexene oxidation in a jet-stirred reactor at $\varphi=0.5,1.0$ and 2.0, $\mathrm{P}=106.7 \mathrm{kPa}, \tau=2 \mathrm{~s}$. Cross symbols are SPI-TOF-MS experiments and lines simulations.

The experimental temperature mole fraction evolutions of these hydroperoxides and $\mathrm{H}_{2} \mathrm{O}_{2}$ as a function of temperature are plotted in Figure 18. Compared to a same comparison made during the 
oxidation of $n$-pentane [15] under same conditions, the $\mathrm{H}_{2} \mathrm{O}_{2}$ mole fraction is three times larger during 1-hexene oxidation, showing that the formation of hydrogen peroxide, and consequently of $\mathrm{HO}_{2}$ radicals, is significantly favored during alkene oxidation. This explains the important effect of the reactions involving $\mathrm{HO}_{2}$ radicals, as shown in Figure 4b. Alkenyl hydroperoxides are formed in lower amounts than $\mathrm{C}_{1}-\mathrm{C}_{2}$ alkylhydroperoxides. However the $\mathrm{CH}_{3} \mathrm{OOH} / \mathrm{C}_{3} \mathrm{H}_{5} \mathrm{OOH}$ ratio at the peak maximum is equal to a factor of 6.5 during 1-hexene oxidation, while it was a factor of about 15 during $n$-pentane oxidation.

Figure 16 displays the experimental and simulated evolutions of the hydroperoxide mole fraction as a function of temperature for the three studied equivalence ratios. For a given temperature above $600 \mathrm{~K}$, the experimental mole fractions of methyl, ethyl and allylhydroperoxides gradually increases when $\phi$ decreases. The situation is different for the other compounds, where the mole fraction increases when $\phi$ decreases from rich to stoichiometric mixtures, but where the mole fraction at $\phi=$ 0.5 is lower than those at $\phi=1.0$.

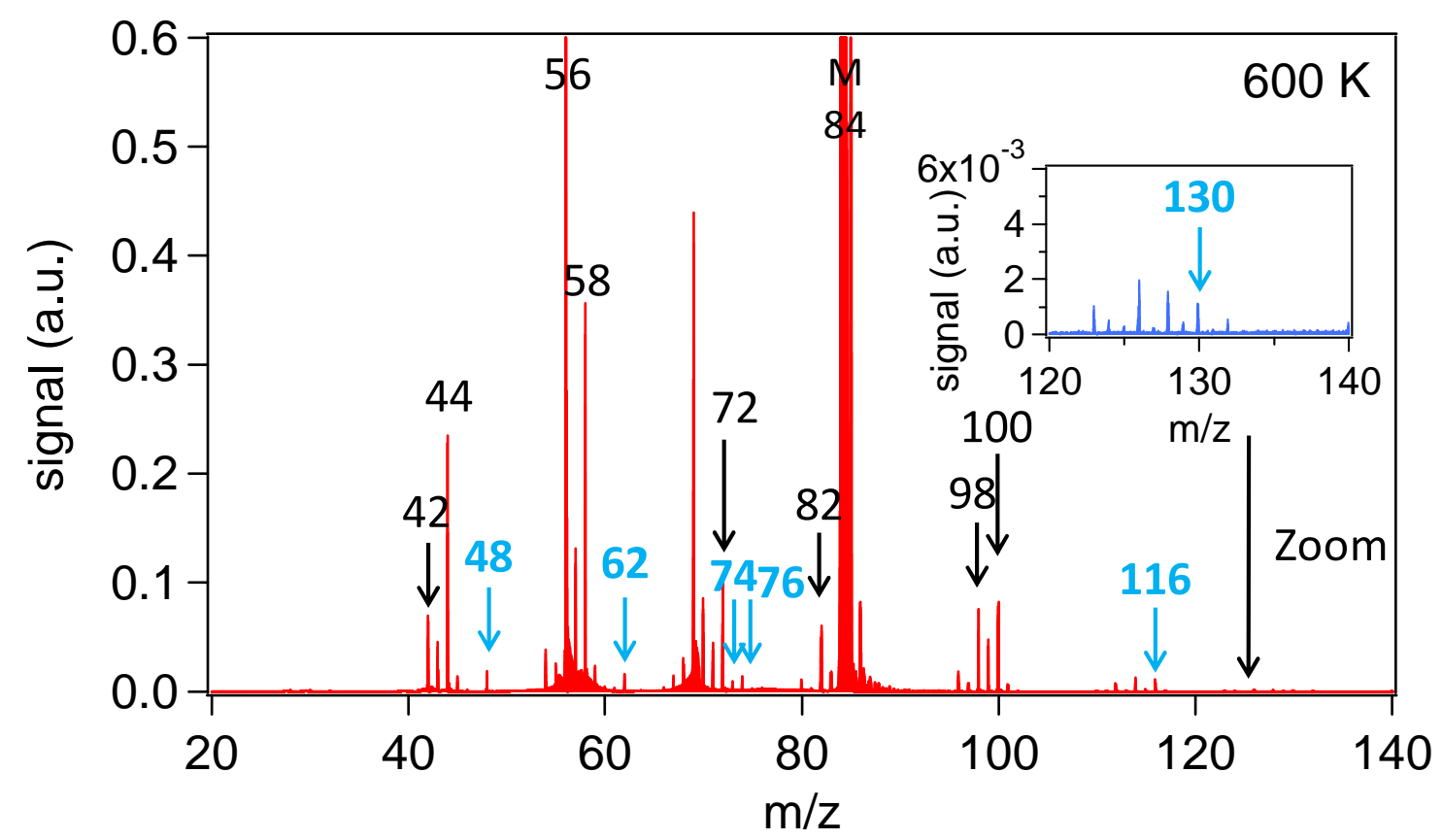

Figure 17: Mass spectrum obtained during stoichiometric 1-hexene oxidation at $600 \mathrm{~K}$ using SPI-TOFMS. Numbers in blue bold are $\mathrm{m} / \mathrm{z}$ corresponding to hydroperoxides.

Except from ketohydroperoxides, the mole fractions of all hydroperoxides are well reproduced by the model, taking into account the large experimental uncertainty due to estimated PICS. A still larger unexplained overprediction of ketohydroperoxides (a factor of 125) was observed during n-pentane oxidation using the same experimental method and a recent kinetic model [15] and would deserve further studies. With the previously described pressure dependence considered for $\mathrm{C}_{3+}$ hydroperoxide decomposition, the temperatures of the mole fraction maxima are satisfactorily predicted. This is also the case for methyl and ethyl hydroperoxides, for which the influence of $\phi$ is also well predicted, while it is not the case for $\mathrm{C}_{3}$ hydroperoxides. 


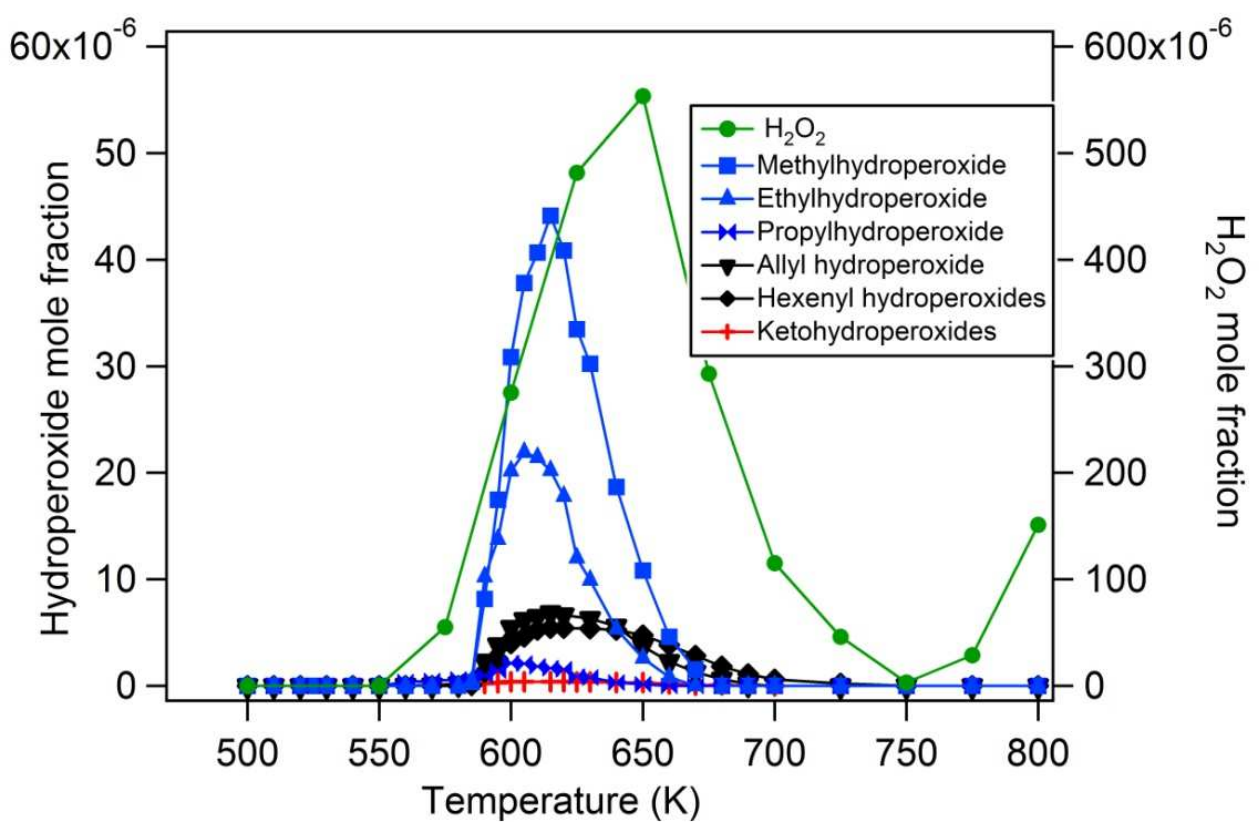

Figure 18: Mole fraction profiles of all the peroxides detected during 1-hexene oxidation in a jet-stirred reactor at $\mathrm{f}=1.0, \mathrm{P}=106.7 \mathrm{kPa}, \tau=2 \mathrm{~s}$. Cross symbols are SPI-TOF-MS experiments and lines are only a guide for the eye.

\section{Flow rate analyses}

Figure 19 displays an overview of the 1-hexene oxidation reaction flux at $650 \mathrm{~K}$ under stoichiometric conditions. The addition of hydroxyl radical to the fuel double bonds plays a major role in consuming the fuel at low temperature, accounting for $35.4 \%$ of the total flux. Since the rate constant used for additions followed by decomposition (pathway not shown in Figure 19) is low according to the theoretical work of Zádor et al. [13], fuel consumption via this pathway is less than $0.1 \%$ and much less important than through the reaction forming the stabilized adduct.

The two radical adducts both subsequently lead to addition to molecular oxygen and isomerization via the Waddington mechanism, but with different branching ratios. A large fraction $(70.6 \%)$ of 1-hydroxyhex-2-yl radicals yielded from the terminal-atom addition primarily adds to molecular oxygen, and successively produces formaldehyde and pentanal via the Waddington mechanism. This is the main pathway for the low-temperature production of pentanal. By contrast, only $3.5 \%$ of the 2-hydroxy-1-hexyl radical adds to molecular oxygen followed primarily by the Waddington mechanism. 86.7\% of 2-hydroxy-1-hexyl radicals yielded from the central atom addition mainly react through a six-membered ring isomerization, while only $18.7 \%$ of 1-hydroxyhex-2-yl radicals are consumed via such a channel. 1-Hydroxyhex-2-yl radical and 2-hydroxyhex-1-yl radicals both can isomerize via a two-step pathway to $\alpha$-hydroxyalkyl radicals, which are mostly subsequently oxidized to form hexanal and 2-hexanone, respectively, both detected during the previously described JSR experiments.

For the $\mathrm{C}_{6} \mathrm{H}_{12} \mathrm{OHOO}$ radicals produced from both adducts, there is a competing pathway with the Waddington mechanism: these radicals can also give hydroxyhydroperoxyalkyl radicals via a sevenmembered ring isomerization, followed primarily by the formation of cyclic ethers bearing an alcohol function. In case of 1-hydroxyhex-2-yl radical, 2-methyl,5-hydroxymethyl-tetrahydrofuran is yielded, which was detected in the previously described experiments. To a lesser extent, these 
hydroxyhydroperoxyalkyl radicals can also add to oxygen and give hydroxyketohydroperoxides, the decomposition of which is a major branching step.

$650 K \varphi=1$

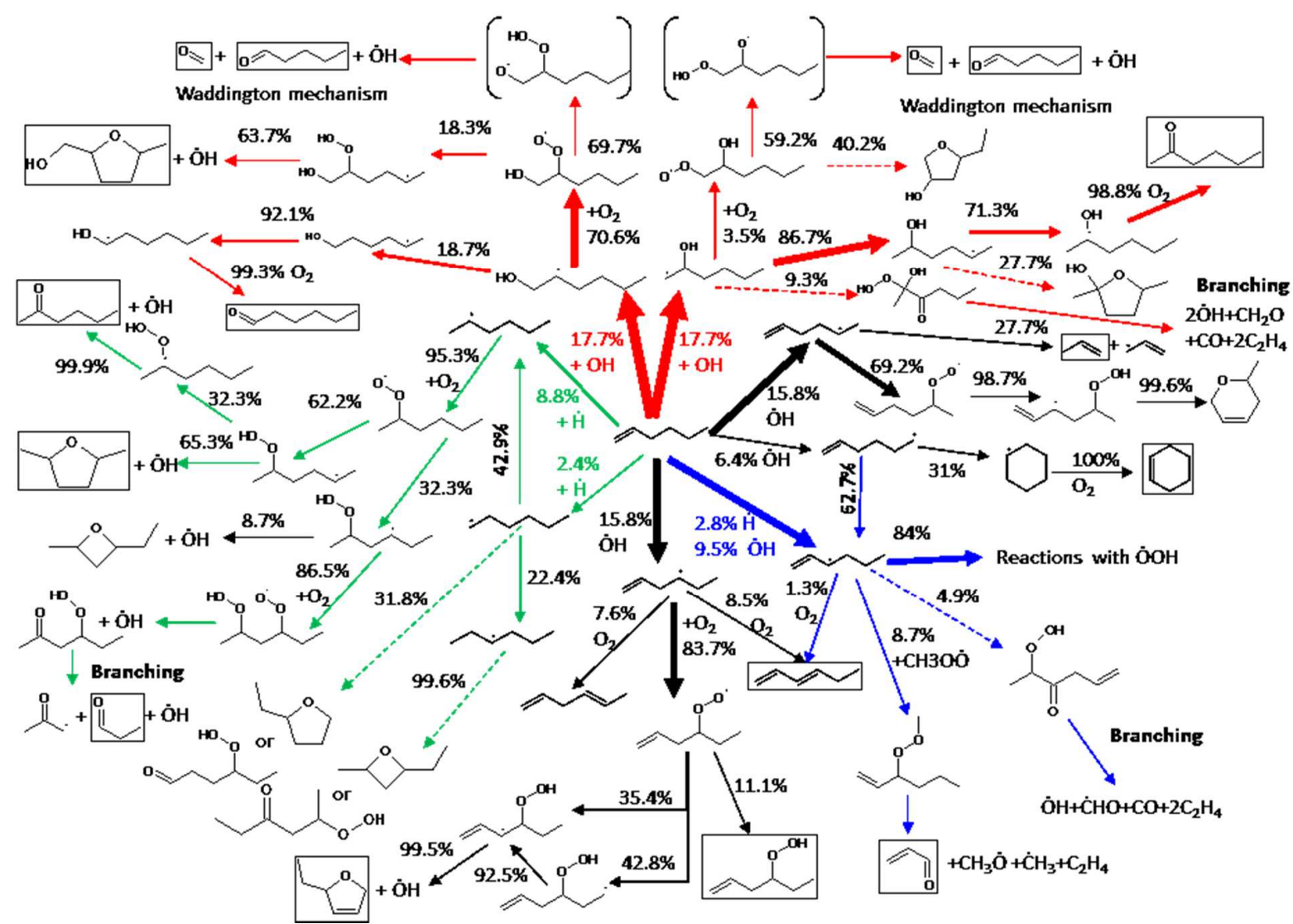

Figure 19: Reaction flux for 1-hexene oxidation computed at $650 \mathrm{~K}, \phi=1$; species in boxes were detected during the JSR experiments. Broken arrows correspond to several elementary steps; numbers with arrows correspond to the flux of intermediate consumption.

The additions of an $\mathrm{H}$ atom to the double bond are another notable low-temperature fuel consuming pathway, although less important than the ÖH additions. The terminal-atom addition is favored. The obtained hex-2-yl radical mainly (95.3\%) adds to molecular oxygen producing the peroxyl radical $\mathrm{C}_{6} \mathrm{H}_{13} \mathrm{OO}$. The peroxyl radical $\mathrm{C}_{6} \mathrm{H}_{13} \mathrm{OO}$ subsequently isomerizes to ${ }^{\circ} \mathrm{QOOH}$ radicals via six-membered ring $(32.3 \%)$ or seven-membered ring $(62.2 \%)$ transition states. The most favored $\mathrm{QOOH}$ radical cyclizes to form 2,5-dimethyltetrahydrofuran, which was detected during the previously described JSR experiments. However, the other $\mathrm{QOOH}$ radical is mainly consumed by a second addition to $\mathrm{O}_{2}$, leading to the production of ketohydroperoxides, the decomposition of which is also a major branching step and contributes to the low-temperature production of propanal as mentioned earlier.

The pathways competing with fuel consumption with radical additions are $\mathrm{H}$-atom abstractions, mainly by hydroxyl radicals, which consume nearly $50 \%$ of the fuel. The products are alkenyl radicals. The hex-1-en-4-yl and hex-1-en-5-yl radicals mainly add to $\mathrm{O}_{2}$ to give peroxyl radicals which isomerize to yield $\mathrm{QOOH}$ radicals. These unsaturated $\mathrm{QOOH}$ radicals are the source of cyclic ethers with double bonds inside the ring and of $\mathrm{C} 6$ unsaturated ketohydroperoxides, the decomposition of which is a third major branching step. The hex-1-en-6-yl radical mostly isomerizes to give the allylic 
radical, while the competing pathway is the formation of cyclohexyl radical, which subsequently produces cyclohexene.

The allylic, hex-1-en-3-yl, radical is predominantly consumed through reactions with $\mathrm{HO}_{2}$ radical. As shown in Figure 20, with the delocalized electrons, the reaction of the allylic and $\mathrm{HO}_{2}$ radicals leads to two distinct reactions pathways. The two obtained allyloxy radicals can be either directly produced or yielded through the decomposition of an intermediate allylhydroperoxide. The hex-1-en-3-oxy radical decomposes to acrolein and propyl radical, while the hex-2-en-1-oxy radical mainly produces 2-hexenal with the competing pathways yielding 1-pentene and formyl radical. The impressive overprediction of 2-hexenal with the present model, which is shown in Figure 14, indicates that there is still a significant incertitude about the kinetics of the channels involved by the reaction of hex-1en-3-yl and $\mathrm{HO}_{2}$ radicals.

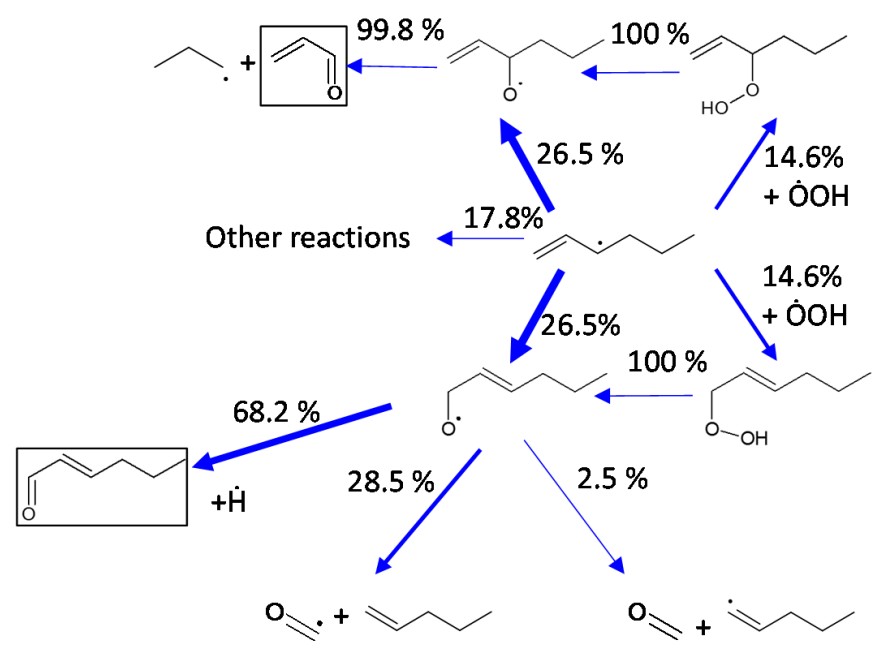

Figure 20: Detailed reaction flux of the reactions of allylic radical hex-1-en-3-yl with the HO2 radical computed for 1-hexene oxidation at $650 \mathrm{~K}, \phi=1$. Numbers with arrows correspond to the flux of intermediate consumption.

The importance of the three major branching steps previously described is also indicated by the sensitivity analysis performed at $650 \mathrm{~K}$ and displayed in Fig. S9 of the SM. The largest promoting effect on the reactivity is observed for the abstraction of allylic $\mathrm{H}$-atoms by $\mathrm{OH}$ radicals. The addition to oxygen of the $\mathrm{R}^{2} 1 \mathrm{C}_{6} \mathrm{H}_{12} \mathrm{OH}$ radical also shows a significant promoting effect. This former radical is formed by isomerization of one adduct directly obtained via $\dot{\mathrm{O}} \mathrm{H}$ addition to 1-hexene $\left(\mathrm{R}_{2} 8 \mathrm{C}_{6} \mathrm{H}_{12} \mathrm{OH}\right.$

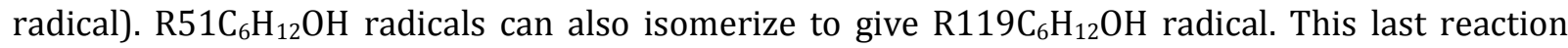

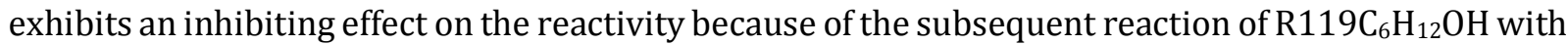
$\mathrm{O}_{2}$ yielding hexanal and unreactive $\mathrm{HO}_{2}$ radicals. Finally the addition of $\mathrm{H}$-atoms to 1-hexene displays also a notable promoting effect.

When the reaction temperature is increased up to $850 \mathrm{~K}$, the addition of hydroxyl radicals becomes less important in consuming the fuel, accounting for less than $10 \%$ as shown in Figure S8 in the SM. As a result, the formation of pentanal and 2-methyl,5-hydroxymethyl-tetrahydrofuran is greatly reduced as shown in the previously described experiments.

At $850 \mathrm{~K}$, the addition of $\mathrm{H}$-atoms, and $\mathrm{H}$-atom abstractions have a more important roles in fuel consumption. $\beta$-Scissions are more competitive compared to addition to $\mathrm{O}_{2}$ of the obtained radicals. $16.5 \%$ of 1 -hexene is added to the $\mathrm{H}$-atom to form hex-2-yl radical, the fate of which is mainly 
decomposition through $\beta$-scission. The contribution of addition to oxygen of this radical drops dramatically to $20.7 \%$ compare to the $95.3 \%$ at $650 \mathrm{~K}$. The peroxyl radical is also less likely to go through a second addition of $\mathrm{O}_{2}$. Instead, it is more prone to isomerize and yield cyclic ethers, or decompose via $\beta$-scission.

At $850 \mathrm{~K}$, the alkenyl radicals produced by $\mathrm{H}$-atom abstraction are also more likely to go through $\beta$-scission to produce alkenes and dienes. The hex-1-en-6-yl radical is mainly cyclized to produce cyclohexyl radical, a source of cyclohexene. The production of allylic, hex-1-en-3-yl, radical is almost doubled at $850 \mathrm{~K}$ compared to that of $650 \mathrm{~K}$. More than $80.0 \%$ of this radical is decomposed to produce 1,3-butadiene and ethyl radical. Only $12 \%$ of the hex-1-en-3-yl radicals react with $\mathrm{HO}_{2}$ radicals, less than a fourth of the proportion at $650 \mathrm{~K}$. The two allyloxy radicals are predominantly produced via the direct reaction of hex-1-en-3-yl and $\mathrm{HO}_{2}$ radicals, while the formation of allylhydroperoxides is much less favored than at high temperature.

Since important deviations were observed between experiments and modeling (see Figure 14), a sensitivity analysis was also performed for the mole fraction of 2-hexenal at $650 \mathrm{~K}$ and $\phi=1$ to highlight reactions sensitive for the production and consumption of this species (see Figure S10a in SM). Reactions which have a large effect on the mole fraction of 2-hexenal are $\mathrm{H}$-atom abstractions from the fuel. H-atom abstractions forming the hex-1-en-3-yl radical (shown in Figure 19) have a positive effect, whereas $\mathrm{H}$-atom abstractions forming other fuel radicals have a competitive negative effect. An exception is the formation of the hex-1-en-6-yl radical, of which $62.7 \%$ isomerizes to the hex-1-en-3-yl radical (see Figure 19). Another sensitive inhibitive reaction is the decomposition of the hex-2-en-1-oxy radical to 1-pentene and CंHO radical that directly competes with the formation of 2-hexenal (see Figure 20). The consumption channels of oxy radicals were very rarely studied and models would benefit of more work on this type of species deriving from the decomposition of hydroperoxides. Reactions of the hex-2-en-1-oxy radical are not sensitive for the global reactivity (see Fig. S9 in SM) and modifying their kinetic parameters would not affect the global reactivity. Similar observations can be done for the $\mathrm{C} 6$ unsaturated cyclic ethers, which were also overestimated at low temperature (see Figure 15). The most sensitive positive reactions for their formation is the H-atom abstractions from the fuel forming hex-1-en-4-yl radicals $\left(\mathrm{R}_{2} 3 \mathrm{C}_{6} \mathrm{H}_{11} \mathrm{Z}\right.$ in the sensitivity graph in Figure $\mathrm{S} 10 \mathrm{~b}$ in SM) which is the precursor of this cyclic ether. The most negative sensitive reaction is the $\mathrm{H}$-atom abstraction by $\mathrm{OH}$ consuming the $\mathrm{C}_{6}$ unsaturated cyclic ethers. $\mathrm{C}_{6}$ unsaturated cyclic ethers have been very rarely studied and refining the kinetic parameters of their $\mathrm{H}$-atom abstractions would lead to a more reliable chemistry.

\section{Conclusion}

The present paper describes a new model for 1-hexene oxidation based on the recent literature theoretical studies concerning the elementary reactions related to alkenes. The major updated reactions have been the reactions of $\mathrm{OH}$ radicals with the fuel, the Waddington mechanism, the combinations of allylic and $\mathrm{HO}_{2}$ radicals, the $\alpha$-hydroxyalkyl radical oxidation, and the reaction of ketohydroperoxides. Taking into account the described updates, the new model can satisfactorily reproduce literature data obtained in a rapid compression machine, but also the new experimental results obtained in this work for equivalence ratios from 0.5 to 2 . These results also include quantification of hydrogen peroxide, and alkyl-, alkenyl- and ketohydroperoxides. Comparison of experimental and simulated results for carbon containing hydroperoxides show that more work is still needed to fully understand the chemistry of these compounds, which are of key importance for autoignition. 


\section{Acknowledgments}

Xiangzan Meng would like to acknowledge the financial support from the program of China Scholarship Council (NO. 201506250038).

\section{Supplementary materials}

- $\quad$ Experimental data for the oxidation of 1-hexene

- $\quad$ Kinetic model with thermochemical data and species glossary

- $\quad$ Supplementary description

\section{References}

[1] J.C. Guibet Fuels and engines. Paris, Publications de l'Institut Français du Pétrole, Editions Technip (1999).

[2] M. Ribaucour, R. Minetti, L.R. Sochet, Autoignition of n-pentane and 1-pentene: Experimental data and kinetic modeling, Proc. Combust. Inst. 27 (1998) 345-351.

[3] R. Minetti, A. Roubaud, E. Therssen, M. Ribaucour, L.R. Sochet, The chemistry of pre-ignition of n-pentane and 1-pentene, Combust. Flame 118 (1999) 213-220.

[4] G. Vanhove, M. Ribaucour, R. Minetti, On the influence of the position of the double bond on the low-temperature chemistry of hexenes, Proc. Combust. Inst. 30 (2005) 1065-1072.

[5] S. Touchard, R. Fournet, P.A. Glaude, V. Warth, F. Battin-Leclerc, G. Vanhove, M. Ribaucour, R. Minetti, Modeling of the oxidation of large alkenes at low temperature, Proc. Combust. Inst. 30 (2005) 1073-1081.

[6] M. Mehl, T. Faravelli, F. Giavazzi, E. Ranzi, P. Scorletti, A. Tardani, D. Terna, Detailed Chemistry Promotes Understanding of Octane Numbers and Gasoline Sensitivity, Energy Fuels 20 (2006) 23912398.

[7] M. Mehl, G. Vanhove, W.J. Pitz, E. Ranzi, Oxidation and combustion of the $\mathrm{n}$ hexene isomers: A wide range kinetic modeling study, Combust Flame 155 (2008) 756-772.

[8] R. Bounaceur, V. Warth, B. Sirjean, P.A. Glaude, R. Fournet, F. Battin-Leclerc, Influence of the position of the double bond on the autoignition of linear alkenes at low temperature, Proc. Combust. Inst. 32 (2009) 387-394.

[9] M. Mehl, W.J. Pitz, C.K. Westbrook, K. Yasunaga, C. Conroy, H.J. Curran, Autoignition behavior of unsaturated hydrocarbons in the low and high temperature regions, Proc. Combust. Inst. 33 (2011) 201-208.

[10] F. Battin-Leclerc, A. Rodriguez, B. Husson, O. Herbinet, P.-A. Glaude, Z. Wang, Z. Cheng, F. Qi, Products from the Oxidation of Linear Isomers of Hexene, J. Phys. Chem. A. 118 (2014) 673-683.

[11] F. Yang, F. Deng, P. Zhang, Z. Tian, C. Tang, Z. Huang, Experimental and Kinetic Modeling Study on trans-3-Hexene Ignition behind Reflected Shock Waves, Energy Fuels. 30 (2016) 706-716.

[12] S. Tanaka, F. Ayala, J.C. Keck, J.B. Heywood, Two-stage ignition in HCCI combustion and HCCI control by fuels and additives, Combustion and Flame. 132 (2003) 219-239.

[13] J. Zádor, A.W. Jasper, J.A. Miller, The reaction between propene and hydroxyl, Phys. Chem. Chem. Phys. 11 (2009) 11040-11053.

[14] J.C. Lizardo-Huerta, B. Sirjean, R. Bounaceur, R. Fournet, Intramolecular effects on the kinetics of unimolecular reactions of $\beta$-HOROO' and HOQ OOH radicals, Phys. Chem. Chem. Phys. 18 (2016) 12231-12251.

[15] A. Rodriguez, O. Herbinet, Z. Wang, F. Qi, C. Fittschen, P. Westmoreland, Measuring hydroperoxide chain-branching agents during n-pentane low-temperature oxidation, Proc. Combust. Inst., 36 (2016) in press http://dx.doi.org/10.1016/j.proci.2016.05.044. 
[16] O. Herbinet, F. Battin-Leclerc, Progress in understanding low-temperature organic compound oxidation using a jet-stirred reactor, Int. J. Chem. Kin. 46 (2014) 619-639.

[17] O. Herbinet, G. Dayma, Jet-stirred reactor, in: F. Battin-Leclerc, J.M. Simmie, E. Blurock (Eds.), Cleaner Combustion, Springer London, 2013, pp. 183-210.

[18] J. Tranchant, Chromatographie en phase gazeuse; Ed. Techniques Ingénieur (1996).

[19] C. Bahrini, P. Morajkar, C. Schoemaecker, O. Frottier, O. Herbinet, P.-A. Glaude, F. BattinLeclerc, C. Fittschen, Experimental and modeling study of the oxidation of n-butane in a jet stirred reactor using cw-CRDS measurements, Phys. Chem. Chem. Phys. 15 (2013) 19686-19698.

[20] Reaction Design. CHEMKIN-PRO 15151. San Diego: 2016.

[21] E. Blurock, F. Battin-Leclerc, T. Faravelli, W. Green, Automatic generation of detailed mechanisms, in: F. Battin-Leclerc, J.M. Simmie, E. Blurock (Eds.), Cleaner Combustion, Springer London, 2013, pp. 59-92.

[22] S.W Benson, Thermochemical Kinetics, 2nd ed., John Wiley, New York (1976).

[23] C. Muller, V. Michel, G. Scacchi, G.M. Côme. Thergas - a computer program for the evaluation of thermochemical data of molecules and free-radicals in the gas phase. J. Chim. Phys. 92 (1995) 11541178.

[24] J. Troe, The thermal dissociation/recombination reaction of hydrogen peroxide III.: Analysis and representation of the temperature and pressure dependence over wide ranges, Combust. Flame 158 (2011) 594-601.

[25] D.L. Baulch, C.J. Cobos, R.A. Cox, P. Frank, G. Hayman, T. Just, et al., Evaluated Kinetic Data for Combustion Modeling. Supplement I. J. Phys. Chem. Ref. Data 23 (1994) 847-848.

[26] C.F. Goldsmith, S.J. Klippenstein, W.H. Green, Theoretical rate coefficients for allyl + HO2 and allyloxy decomposition, Proc. Combust. Inst. 33 (2011) 273-282.

[27] C.F. Goldsmith, W.H. Green, S.J. Klippenstein, Role of $02+$ QOOH in Low-Temperature Ignition of Propane. 1. Temperature and Pressure Dependent Rate Coefficients, J Phys Chem A 116 (2012) $3325-3346$.

[28] K. Zhang, C. Banyon, C. Togbé, P. Dagaut, J. Bugler, H.J. Curran, An experimental and kinetic modeling study of n-hexane oxidation. Combust. Flame 162 (2015) 4194-4207.

[29] G. da Silva, J.W. Bozzelli, L. Liang, J.T. Farrell, Ethanol Oxidation: Kinetics of the $\alpha$-Hydroxyethyl Radical + 02 Reaction, J. Phys. Chem. A 113 (2009) 8923-8933.

[30] D.L. Baulch, C.J. Cobos, R.A. Cox, C. Esser, P. Frank, T. Just, et al., Evaluated Kinetic Data for Combustion Modelling. J. Phys. Chem. Ref. Data 21 (1992) 411-734.

[31] C. Kappler, J. Zádor, O. Welz, R.X. Fernandez, M. Olzmann, C.A. Taatjes, Competing channels in the propene $+\mathrm{OH}$ reaction: experiment and validated modeling over a broad temperature and pressure range. Z. Für Phys. Chem. 225 (2011) 1271-1291.

[32] S.S. Vasu, L.K. Huynh, D.F. Davidson, R.K. Hanson, D.M. Golden, Reactions of OH with Butene Isomers: Measurements of the Overall Rates and a Theoretical Study, J. Phys. Chem. A. 115 (2011) 2549-2556.

[33] Y. Li, C.-W. Zhou, K.P. Somers, K. Zhang, H.J. Curran, The oxidation of 2-butene: A high pressure ignition delay, kinetic modeling study and reactivity comparison with isobutene and 1-butene, Proc. Combust. Inst., 36 (2016) in press, doi:10.1016/j.proci.2016.05.052.

[34] M.S. Stark, D.J. Waddington, Oxidation of propene in the gas-phase. Int. J. Chem. Kinet. 27 (1995) 123-151.

[35] S.M. Burke, W. Metcalfe, O. Herbinet, F. Battin-Leclerc, F.M. Haas, J. Santner, F.L. Dryer, H.J. Curran, An experimental and modeling study of propene oxidation. Part 1: Speciation measurements in jet-stirred and flow reactors, Combust. Flame. 161 (2014) 2765-2784.

[36] J. Zádor, R.X. Fernandes, Y. Georgievskii, G. Meloni, C.A. Taatjes, J.A.Miller, The reaction of hydroxyethyl radicals with 02: A theoretical analysis and experimental product study. Proc. Combust. Inst. 32 (2009) 271-277. 
[37] S.M. Sarathy, P. Oßwald, N. Hansen, K. Kohse-Höinghaus, Alkohol combustion chemistry. Prog. Energy Combust. Sci. 44 (2014) 40-102.

[38] H.J. Curran, P. Gaffuri, W.J. Pitz, C.K. Westbrook, A comprehensive modeling study of isooctane oxidation, Combust. Flame. 129 (2002) 253-280.

[39] K.A. Sahetchian, A. Heiss, R. Rigny, R.I. Ben-aïm, Determination of the gas-phase decomposition rate constants of heptyl-1 and heptyl-2 hydroperoxides $\mathrm{C} 7 \mathrm{H} 150 \mathrm{OH}$, Int. J. Chem. Kinet. 14 (1982) 1325-1337.

[40] C.F. Goldsmith, M.P. Burke, Y. Georgievskii, S.J. Klippenstein, Effect of non-thermal product energy distributions on ketohydroperoxide decomposition kinetics. Proc. Combust. Inst. 35 (2015) 283-290.

[41] M. Yahyaoui, N. Djebaïli-Chaumeix, C.-E. Paillard, S. Touchard, R. Fournet, P.A. Glaude, F. Battin-Leclerc, Experimental and modeling study of 1-hexene oxidation behind reflected shock waves, Proc. Combust. Inst. 30 (2005) 1137-1145. 